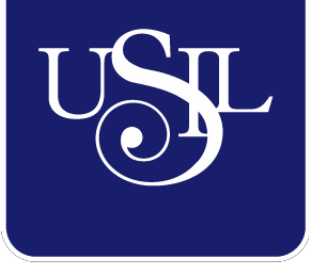

UNIVERSIDAD

SAN IGNACIO

DE LOYOLA

FACULTAD DE CIENCIAS EMPRESARIALES

Carrera de International Business

\title{
INFLUENCIA DEL BRANDING DE UN RETAIL MULTINACIONAL DE MODA EN LA ADQUISICIÓN DE PRODUCTOS EN TRABAJADORES DE SURCO
}

Tesis para optar el Título Profesional de Licenciado en International Business

CLAUDIA PAOLA LINARES SALAZAR (0000-0002-7899-4848)

\section{Asesor: \\ JORGE RAFAEL SANTILLÁN BARCELLOS}

(0000-0002-9715-1686)

Lima- Perú

2020 
El presente proyecto de investigación se lo dedico a mis padres, sin ellos no habría nada de lo logrado hasta ahora, me han apoyado en cada paso aun cuando no estuviesen de acuerdo con mis decisiones, me han sabido aconsejar y dar la independencia necesaria para desarrollarme no solo personalmente sino profesionalmente, Isabel Salazar y José Luis Linares, gracias por todo lo brindado y enseñado, nunca dejaré de estar agradecida y espero algún día poder retribuirles por todo, los amo mucho, esta tesis se la dedico a ustedes, porque todo esfuerzo que hago es siempre motivado por ustedes. 


\section{AGRADECIMIENTOS}

A mis padres, porque me motivaron a no dejar de realizar mi proceso de titulación luego de haber egresado, porque siempre han sido los que me han ayudado a lograr todo lo que me proponía gracias a su motivación y buenos consejos he llegado a donde estoy y seguiré trabajando por más. Gracias mamá por los cafés y snacks en cada desvelo, por tu comprensión cuando hacia ruido en la madrugada y tu ayuda.

A mi hermana, Denis Muñoz, que cuando me vio sufriendo en cursos de la universidad me dijo que no me rindiera, enseñándome siempre la perseverancia, porque me apoyo desde pequeña en mis estudios y mis metas, porque, aunque muchos años estuvo lejos de mi físicamente, siempre me supo alentar cuando lo necesitaba, gracias a mi hermana favorita.

A Linda, quien se amanecía cada noche de estudio de la universidad conmigo, mi compañera en cada desvelo desde el 2008 hasta ahora, me mantenía despierta y su compañía me motivaba a continuar. 


\section{RESUMEN}

En los últimos años, los retails multinacionales de moda han utilizado diversas herramientas para que las personas consuman sus productos y al ser cada vez un mundo más globalizado han tenido que enfrentar grandes cambios y nuevos competidores alrededor del mundo. Es así que muchas grandes empresas han aplicado el branding para resaltar la proposición única que proponen y evitar que los nuevos entrantes al mercado reduzcan su participación actual, sin embargo, se mantiene la incógnita sobre su verdadera eficiencia frente a otras herramientas de marketing y comercialización, especialmente para los tipos de brand awareness, branding sensorial y branding digital. Como consecuencia, se propuso la siguiente investigación cuyo propósito es analizar la influencia del branding en la adquisición de productos de un retail multinacional de moda en trabajadores del distrito de Surco, tomando en cuenta su interacción y adquisición de marcas de moda internacional debido a su nivel socioeconómico y su actividad económica. Los resultados de la investigación muestran que existe una influencia del branding en la adquisición de los productos de un retail multinacional de moda en los trabajadores del distrito de Surco, en los tres niveles mencionados por lo que las empresas deberían tomarlo en cuenta para poder saber con exactitud que indicadores podrían provocar mayores ventas tanto por el canal online como presencial y mejorar su rentabilidad.

PALABRAS CLAVES: Branding, brand awareness, retail, influencer, logo, slogan. 


\section{SUMMARY}

In the last few years, the multinational fashion retails have used different tools in order for people to consume their products and due to the actual globalization, they have had to face really big changes and new competitors around the world. Therefore, many companies have started to apply branding tools to highlight their value proposition and to avoid that new entrants reduce their market share. Nevertheless, there is still the question about the true efficiency when facing other marketing and commercialization tools, especially when talking about brand awareness, sensory branding and digital branding. In consequence, the following research was proposed to analyze the branding influence in the acquisition of products in a multinational fashion retail in the workers that live in Surco, taking into consideration their interaction and acquisition of international fashion brands due to their socioeconomic level and their jobs. The results show that there is an influence of the branding over the acquisition of the products in a multinational fashion retail in the workers that live in Surco, in all three different types mentioned above. Therefore, the companies should take it into account to be able to know exactly which indicators could help them have more online and on-site sales as well as have a better return on investment.

KEY WORDS: Branding, brand awareness, retail, influencer, logo, slogan. 


\section{ÍNDICE}

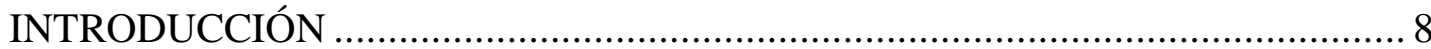

Problema de investigación..................................................................... 9

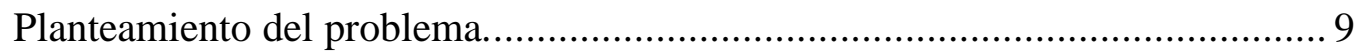

Formulación del problema................................................................... 12

Justificación de la investigación............................................................... 12

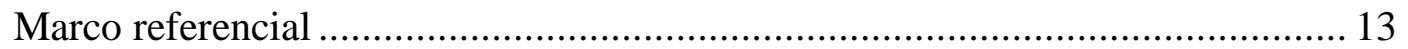

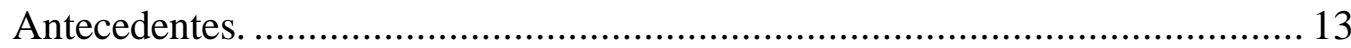

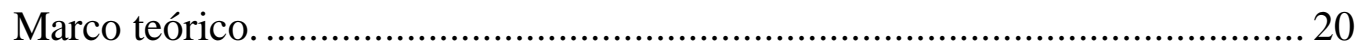

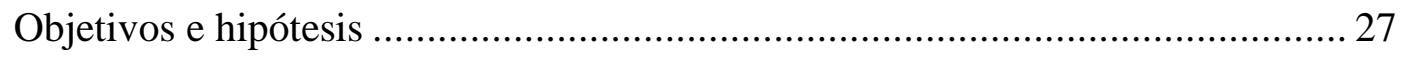

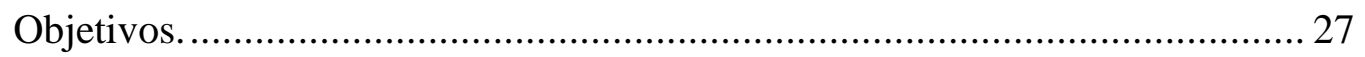

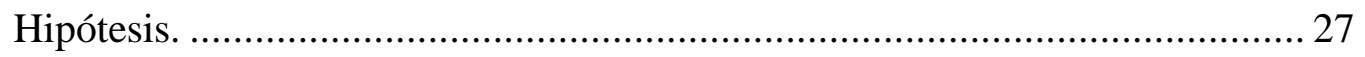

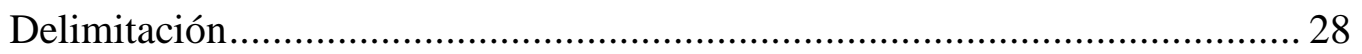

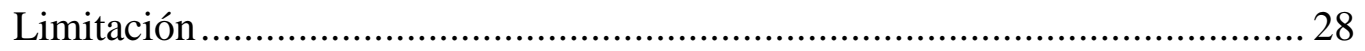

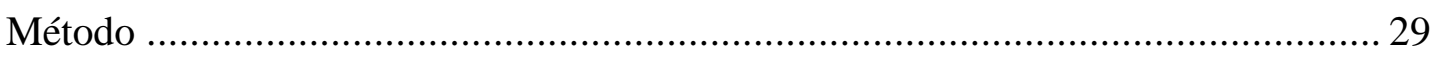

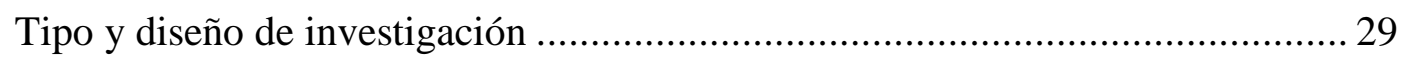

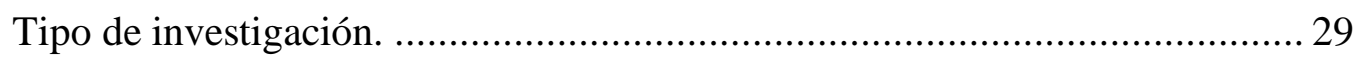

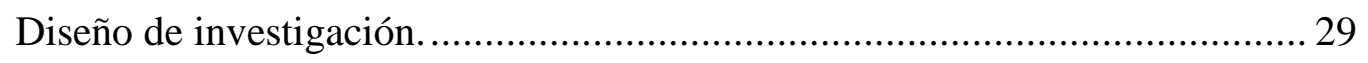

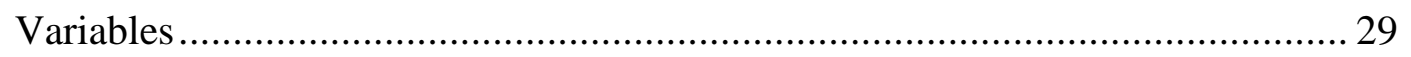

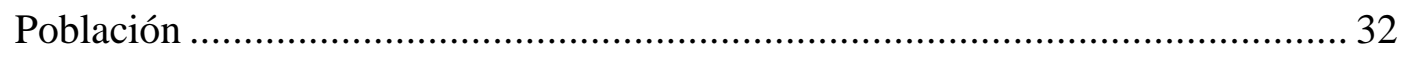

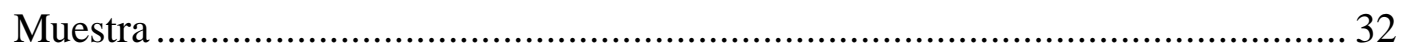




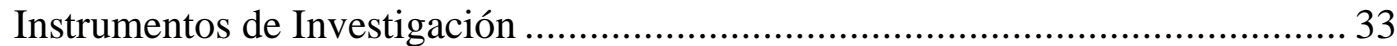

Procedimientos de recolección de datos........................................................... 34

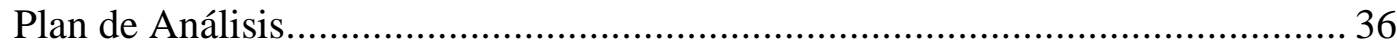

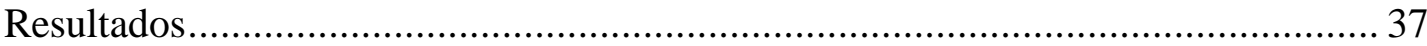

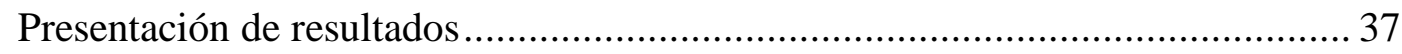

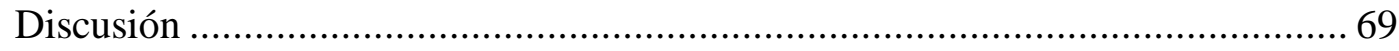

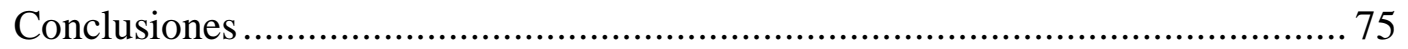

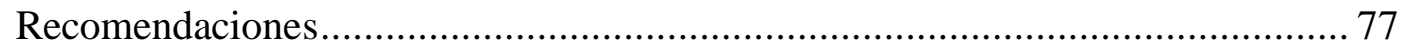

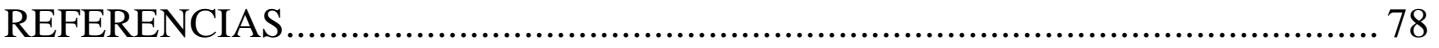

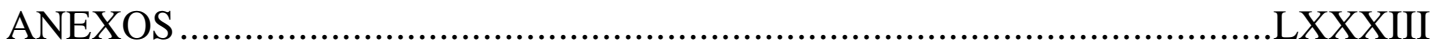




\section{INTRODUCCIÓN}

El objetivo principal del presente proyecto de investigación es identificar la influencia del branding en la adquisición de productos de un retail multinacional de moda en trabajadores del distrito de Surco.

Es así como, en el primer capítulo se aborda el planteamiento del problema, el cual está basado en la influencia que tiene el branding en la adquisición de productos de un retail multinacional de moda, específicamente en trabajadores del distrito de Surco.

En el segundo capítulo se ha realizado el marco referencial, el cual comprende los antecedentes; es decir aquellas investigaciones que fueron realizadas con anterioridad y que generan un aporte para nuestra investigación.

Así como también el marco teórico que presenta las conceptualizaciones teóricas que fundamentan el presente proyecto y el marco conceptual, el cual contiene las definiciones básicas para comprender de forma mucho más fácil el proyecto propuesto. Así mismo se han redactado los objetivos e hipótesis, delimitaciones y limitaciones.

Continuando, en el tercer capítulo detallamos el perfil del método, en el cual se define tanto el tipo como el diseño de investigación considerando una investigación de tipo correlacional causal, conjuntamente se señala el instrumento que será aplicado a la muestra extraída de forma probabilística aleatoria de la población. Habiéndome basado para su realización en la operacionalización de las variables. Además, están presentes los procedimientos que se llevarán a cabo para la aplicación del instrumento.

Finalmente he abordado el plan de análisis para los resultados que se obtendrán al finalizar el trabajo de campo, cronograma, recursos y presupuesto necesario para el desarrollo, concluyendo así con el plan de tesis. 


\section{Problema de investigación}

\section{Planteamiento del problema.}

El siglo XXI ha tenido grandes cambios y avances tanto económicos como sociales y tecnológicos los cuales han provocado importantes transformaciones en el ambiente en el que se desenvuelven los retails multinacionales de moda.

El primer gran cambio que se tiene es el aumento del ingreso real y renta per cápita de la población económicamente activa, en 2010 pasando de 9,551 USD per cápita a 11,428 per cápita en 2019, incrementando así el poder adquisitivo, según datos del banco mundial.

Por otro lado, la globalización ha afectado la forma en que se realizan los negocios hoy en día. Las empresas ya no solo se encuentran en su país de fundación, estos han debido expandirse para reducir costos y obtener recursos tanto humanos como materiales para lograr satisfacer las necesidades de la población actual, según la OFX para el año 2017, las empresas que reportaban gran crecimiento desde bueno al boom eran $63 \%$ del total resaltando como motivos los factores mencionados. Es así como podemos concluir de ello que tanto la presencia como la competencia de las empresas hoy en día no es solo nacional sino global, debiendo fortalecer sus marcas a nivel mundial para lograr competir con el rango de productos nacionales y extranjeros que se ofrecen.

Así mismo, los cambios no solo demográficos mencionados anteriormente sino también los cambios psicográficos en los consumidores han tenido grandes variaciones debido a la globalización y cambios socioculturales. Hoy en día se suele elegir lo que está "en vogue”, es decir, lo que está de moda, aunque esto solo acentúe la demanda por cortos periodos de tiempo, obligando a una constante innovación por parte de la marca. Así mismo, muchas veces lo que está "en vogue" suele estar influenciado por el efecto de las estrellas, es decir, personas que 
consideramos líderes de alguna u otra forma y por lo que solemos consumir lo que estos recomiendan, así como lo que tiene buenos comentarios o reseñas vía online o en persona.

Además, la fuerte globalización de una marca y su respectiva demanda pueden venir de la creatividad, innovación, país de origen y singularidad de sus productos como también puede deberse a la identificación social, la demanda de productos en la industria de moda suele darse influenciado por "selección de pares" o transmitida "boca a boca", ello sumado al advertising vía medios masivos, así como la promoción y patrocinio virtual y tradicional acentúa aún más la demanda.

Como mencionábamos anteriormente, el medio virtual acentúa la demanda y es que gracias al acceso a la tecnología que tenemos hoy en día podemos llegar mucho más lejos, el uso masivo de dispositivos móviles electrónicos y las respectivas aplicaciones que este contiene ha incrementado el uso de las redes sociales, de este modo las empresas tienen la posibilidad de brindar información, así como tener una comunicación rápida y efectiva con el público obteniendo así una retroalimentación virtual global, aumentando las ventas online mundiales en un 9\% respecto del año 2017 al 2018.

Si nos concentramos en la información nacional tenemos que el incremento de ingresos entre la población peruana, de 5,082 USD per cápita en 2010 a 6,977 USD per cápita en 2019, especialmente los jóvenes entre 20 a 35 años ha sido un punto clave para el crecimiento de la industria de la moda en el país, con consumidores que vienen adecuándose al modelo de negocios "fast fashion", el cual explica que se cambia rápidamente de tendencia y la empresa debe estar lista para proporcionar el producto cuando se está aún de moda y no después; es así que los peruanos buscan hoy en día las últimas tendencias con los precios más bajos en lugar de calidad y durabilidad, esto ha ocasionado el crecimiento en ventas de más de 2,000 USD por metro cuadrado al año 2019, con tiendas de hasta 4,000 metros cuadrados. 
Por otro lado, según la Cámara de Comercio de Lima, la preferencia que existe por lo extranjero entre los peruanos ha causado que empresas multinacionales ofrezcan productos no solamente fabricados en el exterior sino también con diseños extranjeros y si además de ello adicionamos el deseo de exclusividad es ahí donde la moda extranjera resalta aún más su importancia al lograr estar no solo a la moda sino vestirse de forma exclusiva al tener algo diferente a lo usual en el país en el que se habita. A setiembre del 2019, eran 763,000 personas de clase alta las que adquirían de reconocidas marcas, esto debido en su mayoría a viajes realizados al extranjero o compras locales.

Finalmente, retomando el punto de vista global, la concientización del cuidado del ambiente ha aumentado en los últimos años, teniendo que el $77 \%$ de la población mundial se encuentra preocupada por el daño que le podemos estar causando al planeta al año 2019. Por lo que las empresas han debido adaptarse a esta nueva tendencia de responsabilidad ambiental implementando políticas que lo resalten, proporcionándoles así una ventaja sobre quienes no las tienen. En el caso de las empresas de moda, políticas como el reciclaje de ropa o descuentos por entrega de ropa están siendo los métodos más aplicados y mejor aceptados por los consumidores actualmente, creando así una imagen de marca eco amigable.

Debido a lo mencionado en estos párrafos podemos concluir que se presenta una ventaja para las empresas actualmente, mejorando el planeamiento y estrategias de marketing y merchandising para mejorar el branding de su empresa. Teniendo como consecuencia una reacción positiva y a favor de la adquisición de los productos de la empresa por parte del público. 


\section{Formulación del problema.}

\section{Problema General}

¿Cuál es la influencia del branding en la adquisición de productos de un retail multinacional de moda en trabajadores del distrito de Surco?

\section{Problemas Específicos}

¿Cuál es la influencia del branding sensorial en la adquisición de productos de un retail multinacional de moda en trabajadores del distrito de Surco?

¿Cuál es la influencia del branding digital en la adquisición de productos de un retail multinacional de moda en trabajadores del distrito de Surco?

¿Cuál es la influencia del brand awareness en la adquisición de productos de un retail multinacional de moda en trabajadores del distrito de Surco?

\section{Justificación de la investigación.}

\section{Justificación Práctica}

El presente proyecto de investigación es importante porque va a contribuir al desarrollo de técnicas en la industria retail demostrando a partir de los resultados como el branding influencia en la adquisición de un producto de cierta empresa en lugar de otra de la misma industria que oferta un producto idéntico.

Por otro lado, aportará conocimientos a las empresas de retail multinacionales sobre los elementos de mayor impacto en un público de niveles socio económico medio y alto para lograr la adquisición de sus productos. Teniendo así una mayor visión de su entorno externo, facilitando la toma de decisiones y generando nuevas estrategias para un mejor desempeño en la industria. 
Así mismo, servirá de base para futuros proyectos e investigaciones que tengan una problemática similar a la presentada brindando datos empíricos sobre el comportamiento del consumidor y sus repercusiones económicas en un retail de moda.

\section{Justificación Metodológica}

Este estudio es relevante ya que se va a construir un instrumento de medición, el cual serán cuestionarios, dirigido a identificar la influencia del branding en la adquisición de productos de un retail multinacional de moda lo cual será útil para futuras investigaciones.

\section{Marco referencial}

\section{Antecedentes.}

\section{Antecedentes Internacionales}

Producto de una exhaustiva revisión de la literatura científica en google académico, Ebsco Host y ProQuest en los últimos 10 años se presenta las investigaciones que se relacionan de forma directa e indirecta.

\section{Directos}

Iwu, Jaiyeoba, Thamage y Opeda (2017) presentaron una investigación referida al impacto del Branding de los retails en el comportamiento del consumidor en Botswana. El objetivo general fue examinar el impacto de la marca de un retail en la personalidad del centro comercial, a su vez este cómo impacta en el producto y la calidad de servicio, como estos mencionados anteriormente impactan en el valor de compra y como el valor de compra impacta en el comportamiento final, así como el impacto general de la marca de un retail en las intenciones de compra en una muestra conformada por 200 consumidores de retails en Gaborone y Francistown, ciudades de Botswana. Como instrumentos se utilizaron encuestas transversales con técnicas de muestra no probabilística, análisis de regresión y correlación. Entre las 
conclusiones se halló que el branding es un buen predictor de la respuesta positiva del consumidor, por lo que la propuesta de valor del branding es considerada un enfoque importante para facilitar el crecimiento a las empresas en Botswana.

Goswami (2015) llevó a cabo un estudio acerca de las estrategias del branding online en las tiendas de retail de moda en India. El objetivo general fue obtener conocimiento sobre el branding online a través de una investigación exploratoria y la identificación de las formas en las cuales los canales digitales son usados para aportar a las marcas en una muestra conformada por cuatro tiendas de moda retail solo online y cuatro retails de moda multicanal. Como instrumento se utilizó el análisis de contenido. Entre las conclusiones se halló que los retails deberían comunicar los valores de sus marcas de forma mucho más explícita y prominentemente a través de sus páginas web para mejorar su posicionamiento y desarrollar una mejor comunicación entre consumidores.

Rowley (2009) realizó una investigación sobre las estrategias del branding online de los retails de moda en Reino Unido. El objetivo general fue reportar una investigación exploratoria que pretende contribuir al conocimiento del branding online y la forma en la que el canal online es usado para apoyar las marcas en una muestra conformada por 16 retail outlets y tres supermercados retails que tienen una participación significativa del mercado en el área de moda. Como instrumento se utilizó el análisis de contenido. Entre las conclusiones se halló que los retails de moda de Reino Unido han preferido el canal virtual y los sitios web para establecer su presencia en la web y la conciencia de marca, aunque aún se deba desarrollar dinamismo en su presencia, ya que hay alcance para desarrollar iniciativas de creación de relaciones y comunidades de las marcas. 


\section{Indirectos}

Morris, Beresford y Hirst (2018) elaboró una investigación referente al impacto de la marca de un retail de comida en la generación del gusto y la expectativa en Reino Unido. El objetivo general fue comprobar si los retails de comida generaban expectativas de calidad diferentes y establecer si estos impactaban en la evaluación sensorial en una muestra conformada por 351 personas de ambos sexos. Como instrumento se utilizaron cuestionarios en línea y pruebas sensoriales utilizando las escalas hedónicas. Entre las conclusiones se halló que los retails de comida de diferentes niveles generan diferentes expectativas en los clientes con respecto a la calidad de sus productos, ya que, aunque se esperaría que las marcas privadas lideren en términos de calidad, este estudio demuestra diferencias significantes entre las expectativas sobre los productos de marca propia de la tienda.

Zhang (2016) investigó como realizar una buena marca de retail en tres ensayos: Antecedentes, resultados y estrategias de inversión en publicidad en Estados Unidos. El objetivo general fue examinar los antecedentes primarios del valor usando dimensiones funcionales $\mathrm{y}$ experienciales de la asociación de marca, proponer y validar los recursos como una medida de resultado del valor de marca, y explorar los efectos de la publicad en diferentes métricas de rendimiento de marca en una muestra conformada por 254 personas de ambos sexos para el primer y segundo ensayo, y 113 retails para el tercer ensayo. Como instrumentos se utilizaron encuestas y fuentes primarias como datos de ventas y gastos de documentos oficiales de empresas. Entre las conclusiones se halló que es importante el enfoque en publicidad y se mostró una imagen más completa de cómo funciona verdaderamente la publicidad.

Jalilvand, Shahin y Vista (2014) efectuaron un estudio en lo tocante a examinar la relación entre el branding y la actitud del consumidor hacia el servicio de banca en Irán. El objetivo fue integrar el valor de la marca basada en el consumidor para un destino turístico y la teoría de 
comportamiento planificado para examinar la relación entre branding y actitudes del consumidor hacia la banca en una muestra conformada por 364 clientes de un banco. Como instrumentos se utilizaron cuestionarios con un muestreo por grupos de múltiples etapas. Entre las conclusiones se halló que para construir el branding se debe considerar la imagen de marca, conciencia de marca, calidad percibida y fidelidad de marca, ya que tienen una relación importante con la creación de la actitud incluyendo actitud afectiva, norma subjetiva, control de comportamiento percibido e intención de comportamiento.

Ho (2012) realizó un estudio exploratorio sobre la relación entre los factores que influencian la percepción del consumidor del Branding de Retails y comportamiento de compra en Taiwán. El objetivo general fue conocer el factor que influencia en la identidad de la marca y el desempeño percibidos de la marca de un retail en una muestra conformada por 450 clientes de tres hipermercados en Taichung, ciudad localizada en Taiwán. Como instrumento se utilizaron cuestionarios. Entre las conclusiones se halló que tanto el posicionamiento percibido en rango y precio tuvieron una influencia positiva en el comportamiento del consumidor, así mismo tanto la comunicación de marca y el desenvolvimiento de marca percibidos tuvieron una influencia positiva en el comportamiento del consumidor, de los cuales fue el desenvolvimiento el que tuvo mayor efecto en el consumidor que cualquier otro factor examinado.

\section{Antecedentes Nacionales}

Producto de una exhaustiva revisión de la literatura científica en Google académico, cibertesis Perú, repositorio institucional PIRHUA y repositorio de tesis - USAT en los últimos 10 años, se presenta las investigaciones que se relacionan de forma directa e indirecta. 


\section{Directos}

Escobar (2017) llevó a cabo una investigación referente al Branding y fidelización del cliente en el centro comercial real plaza de la provincia de Huánuco. El objetivo general fue establecer la relación existente entre el Branding y la fidelización del cliente en el Centro Comercial Real Plaza de la provincia de Huánuco en una muestra conformada por 383 personas de ambos sexos mayores de 18 años asistentes al Centro Comercial Real Plaza Huánuco. Como instrumentos se utilizaron cuestionarios. Entre las conclusiones se halló que el branding tiene una relación significativa con el nivel de fidelización del cliente en el Centro Comercial Real Plaza Huánuco por lo que las estrategias de ello se verán relejadas en la relación positiva de las variables.

Kam (2017) investigó la importancia de la marca en la decisión de compra del consumidor de moda: un cuasiexperimento aplicado a las jóvenes universitarias peruanas del NSE a y b. El objetivo general fue comprobar con dos cuasi experimentos qué tan importantes son las marcas para el consumidor de moda millennial frente a otros factores relevantes en la decisión de compra: el precio y el diseño en una muestra conformada por 200 alumnos de ambos sexos del nivel socioeconómico A y B y edades entre 17 y 21 años de dos universidades localizadas en la ciudad de Lima. Como instrumentos se utilizaron dos cuasi experimentos, con las fases prueba y post-prueba a través de cartillas. Entre las conclusiones se halló que, aunque las marcas sean importantes en la decisión de compra de moda en las peruanas, la mayor influencia que tiene sobre el precio y diseño va a depender del tipo de prenda en adquisición.

\section{Indirectos}

Cortegana, Gonzales y Gonzáles (2018) llevaron a cabo un estudio acerca de los Influencers en la decisión de compra de moda deportiva: estudio del consumo de marcas Adidas, Nike y Puma de Millennials de Lima. El objetivo general fue analizar la relación que existe entre los nueve determinantes de compra de Bae et al y los influencers de Adidas, Nike y Puma en una 
muestra conformada por 4 expertos en moda, 17 jóvenes estudiantes de 23 a 25 años de una universidad y 453 clientes entre 19 a 35 años de las marcas deportivas de tiendas de deporte. Como instrumentos se utilizaron entrevistas a profundidad, focus group y encuestas. Entre las conclusiones se halló que de los nueve factores solo precio, habito, tendencias atractivas y confusión tienen alguna relación con el influencer.

Goetendía (2018) realizó un estudio sobre la influencia de la comunicación de Branding digital de los bancos en su Posicionamiento de marca en hombres y mujeres de 24 a 30 años de NSE B. El objetivo general fue demostrar que el posicionamiento de las marcas de los principales bancos en el Perú es influenciado por la comunicación de su branding digital en una muestra conformada por cinco expertos y 381 jóvenes de 24 a 30 años del NSE B de la zona 7 de la ciudad de Lima. Como instrumentos se utilizaron entrevistas a profundidad y encuestas. Entre las conclusiones se halló que la comunicación de branding digital de los bancos si tiene influencia positiva en el posicionamiento de su marca, ya que los atributos encontrados en los más digitales son los más cercanos al posicionamiento deseado para cada banco.

Albin (2017) presentó una investigación referida a la cultura de marca: La influencia del branding en el emprendimiento del Perú actual: bases para una plataforma de vinculación entre el diseño marcario y los emprendedores. El objetivo general fue analizar la percepción del mismo tema en otros países latinoamericanos, comparando estrategias y resultados de lo ofrecido por el Estado como apoyo al diseño en las empresas además de analizar nuevas ideas de solución propuestas por estos tesistas que podrían ser tomadas como ejemplo para el Perú en una muestra conformada por dos expertos, tres estudios de diseño y pequeñas microempresas. Como instrumentos se utilizaron muestras, encuestas existentes, fuentes, grupos de discusión y observación. Entre las conclusiones se halló que para lograr que clientes potenciales conozcan la existencia de un negocio y la identifiquen es importante la cultura de 
marca como herramienta visual, la que actualmente se encuentra en desarrollo en el Perú por lo que se visualiza como una oportunidad de negocio.

Las investigaciones previamente hechas por los licenciados Iwu, Jaiyeoba, Thamage, Opeda, Goswami, Rowley, Morris, Beresford, Hirst, Zhang, Jalilvand, Shahin, Vista, Ho, Escobar, Kam, Cortegana, Gonzales y Gonzáles, Goetendía y Albin nos aportarán información verídica de las diferentes realidades tanto a nivel nacional como internacional sobre el branding y su influencia en los consumidores de moda a favor de las empresas, con representaciones de población real en los últimos años. En ellas se remarcan los factores y variables que se han proporcionado como influenciadores hacia los consumidores, quienes son los que finalmente deciden si se da la adquisición del producto beneficiando así económicamente a la empresa. Por otro lado, debido a la sociedad de hoy, las marcas deben estar en constante cambio y adaptar su branding a las nuevas tendencias y tecnologías para evitar quedar en el olvido.

Finalmente, las pruebas experimentales obtenidas nos brindan datos empíricos previamente obtenidos tanto en Perú como en otros países, los cuales al relacionarse directamente con el objetivo general de esta investigación pueden ser aplicados luego de realizar algunas adaptaciones principalmente según el objeto de estudio con un alto porcentaje de éxito posible en relación a la implementación de estos resultados con el aumento de consumidores de moda. Esto es posible gracias a las cuidadosas investigaciones presentadas en párrafos anteriores, las cuales establecen que las empresas deberían tener un cambio constante para crecer no solo como empresa sino como marca, creando una presencia satisfactoria para sus consumidores y público en general. 


\section{Marco teórico.}

En las siguientes líneas se presentarán los conceptos que son base para el presente proyecto de investigación, para ello se establecerán definiciones, estrategias y tipos que giran en torno al concepto de Branding.

Philip Kotler y Kevin Keller (2015) definen el branding como "el proceso de dotar productos y servicios con el poder de una marca.” (P. 323).

Philip Kotler y Kevin Keller (2015) explican que el branding crea estructuras mentales que ayudan al consumidor a conocer los productos y/o servicios de forma tal que los ayude a tomar decisiones, proporcionando también valor a la firma. (P. 323).

Así mismo, la Asociación Americana de Marketing (AMA por sus siglas en inglés) define una marca como "un nombre, termino, señal, símbolo o diseño, o una combinación de estos a fin de identificar bienes y servicios de un vendedor o grupo de vendedores logrando diferenciarlos de otros".

Es necesario conocer las necesidades y deseos de los consumidores para lograr tener éxito en branding, esto se logra alineando las estrategias de marca de la empresa tanto interna como externamente.

Así, en primer lugar, se abordan las diferentes estrategias de branding de una empresa (Philip Kotler y Kevin Keller, 2015):

Primera Estrategia: Tenemos la decisión de desarrollar nuevos elementos de marca para el nuevo producto de la empresa. 
Segunda Estrategia: Posibilidad de aplicar alguno de los elementos de las marcas existentes al nuevo producto, utilizando la marca corporativa como una marca que acapara su rango de productos.

Tercera Estrategia: Utilizar la combinación de las estrategias anteriores, creando sub-marcas gracias a la combinación de dos o más de las marcas de productos de la empresa.

Según lo mencionado, los elementos básicos de marca a considerar son nombre, logo, slogan, colores, símbolo, packaging y personalidad (Banco Santander, 2019).

En segundo lugar, se abordan siete tipos principales de branding (Tipos de Marketing, 2019 y Sánchez, 2019):

- Branding Digital: Uso de medios digitales.

- Branding Corporativo: Creación interna de la marca de una empresa para exteriorizarse posteriormente.

- Branding Emocional: Se apela a las emociones para crear una relación con la marca.

- Co-branding: Trabajo conjunto de dos marcas para crear una mayor notoriedad.

- Branding Sensorial: Se apela a los sentidos olfativo, auditivo, táctil, gustativo y/o visual de las personas para crear una asociación hacia la marca.

- Branding Awareness: Creación de conciencia de marca, es decir, la asociación entre un concepto y una marca.

- Cause Branding: Se crea una relación entre una marca y una acción benéfica para la sociedad.

En tercer lugar, se aborda los productos y su adquisición. 
Según Schnarch (2014), un producto es definido como "un grupo de atributos que poseen un nombre descriptivo o genérico", así mismo Cambridge University Press (2019) nos menciona que un producto es "algo manufacturado o producido para ser vendido".

Es así como debemos mencionar lo que resalta Schnarch (2014), un producto puede tomar dos formas: Bienes o servicios.

De acuerdo con Kotler (2013), los bienes y servicios difieren en tangibilidad, variabilidad, separabilidad y caducidad. A continuación, se definirán ambos:

Según Britannica (2019), "los bienes son objetos tangibles producidos y adquiridos para satisfacer los deseos o necesidades percibidos de las personas”.

Existen bienes durables y no durables según Britannica (2019), el primero refiere a bienes con un rango de vida significante mayor a tres años, es decir, longevo; mientras el segundo refiere a bienes que son comprados para su consumo inmediato o casi inmediato y tienen un rango de vida desde minutos hasta tres años.

Existen dos tipos de bienes (Almoguera, 2016) que servirán para esta investigación:

Bienes sustitutivos, aquellos que pueden ser sustituidos fácilmente ya que satisfacen una necesidad similar.

Bienes complementarios, aquellos que en su conjunto satisfacen una misma necesidad.

Por otro lado, según Grönroos (2000), se define a un servicio como un "proceso que consiste en una serie de actividades más o menos intangibles que normalmente [...] tiene lugar en la interacción entre los consumidores y empleados de servicios [...] o sistemas del proveedor de servicios, que son proporcionado como soluciones a los problemas del consumidor.

Existen dos tipos de servicios (Monterroso, 2015) que servirán para esta investigación: 
Servicios "in situ", aquellos en que los prestadores de servicios acuden al lugar en donde el cliente indique o se estableció en el contrato.

Servicios con base en instalaciones son aquellos que se prestan en las instalaciones del prestador.

Por otro lado, para la adquisición de productos se realiza un proceso de decisión por parte del comprador (Kotler, 2013):

- Reconocimiento de la necesidad

- Elección del nivel de participación, es decir, el tiempo y esfuerzo que se invertirá.

- Identificación de alternativas

- Evaluación de alternativas

- Decisión de adquisición

- Comportamiento post-compra, aquello que experimente al utilizar el bien o servicio.

Se tienen diversos participantes en el proceso, aunque en algunos casos todos estos pueden ser una misma persona:

Influyente: Persona o elemento que ejerce una influencia en la decisión de compra.

Decisor: Es quien determina lo que se debe adquirir, en tiempo, modo y lugar.

Comprador: Persona que realiza la adquisición.

Usuario: Es quien finalmente hará uso de aquello que ha sido adquirido.

Evaluador: Es aquel que evalúa y da una opinión sobre los atributos del bien o servicio.

En cuarto lugar, se aborda el retail de moda: 
Según IGI global (2019), los retails de moda "son grupos de empresas que pertenecen a la cadena de suministro de moda llevando bienes y servicios de moda desde fabricantes hasta consumidores".

Considerando el párrafo anterior, según Essays UK (2018), la moda “es una forma de expresión libre, la cual considera ropa, accesorios, belleza, peinados y arte corporal”.

Existen 4 tipos de moda:

- Moda Rápida: Según Musch (2019), refiere a crear rápidamente una tendencia, económica y masiva disponible fácilmente, pasan directo de las pasarelas a las tiendas.

- Moda Lenta: Según Musch (2019), refiere al movimiento cultural de reducir la velocidad de producción y adquisición de moda, usualmente relacionada a la eco moda y moda ética.

- Eco Moda: Según Haddrick (2018), considera ser consciente ambientalmente desde la producción de los materiales que serán utilizados para la fabricación del producto final.

- Moda Ética: Según S. Thomas \& A. Van Kopplen (2002), es una filosofía que informa de las fuentes y producción de cada una de las etapas desde la fabricación hasta llegar al consumidor final, considerando derechos humanos, de propiedad cultural, intelectual y sostenibilidad.

En quinto y último lugar se aborda el tema sobre los clientes:

Según Jurán (1993), un cliente es alguien que ha sido impactado por un producto, es el destinatario de un bien o servicio ofrecido por un suministrador, en una situación contractual, el cliente se denomina comprador. Pero a la vez puede ser consumidor final, usuario o beneficiario. Existen dos tipos de clientes: 
- Clientes reales: Son aquellos que compran o consumen los productos de una empresa.

- Clientes potenciales: Son aquellos que aun cuando no adquieren presentan todas las características y condiciones para hacerlo.

Los clientes en la actualidad son realmente diferentes del pasado, teniendo como características las que se presentan a continuación (PuroMarketing, 2012):

- Están conectados en todo momento a través de sus dispositivos móviles y redes sociales.

- Llegan con mayor facilidad a las personas que los rodean e influyentes compartiendo lo que piensan.

- Esperan que las marcas interactúen con ellos retroalimentándolos.

- Cuentan con más información detallada rápidamente.

- Controlan el ciclo de compra.

\section{Marco Conceptual}

Influencia: Es cuando se conoce a alguien y ahora piensa de una manera que de otro modo no hubiera pensado, o hizo algo que no habría hecho con anterioridad. (Sheldrake, 2011)

Branding: Es el proceso de dotar productos y servicios con el poder de una marca. (Philip Kotler y Kevin Keller, 2015)

Producto: Algo manufacturado o producido para ser vendido. (Cambridge University Press, 2019) 
Adquisición de productos: Es la acción de obtener o comprar bienes y/o servicios, proceso en el que se considera la demanda, su preparación y procesamiento, así como la recepción y aprobación del pago. (Webfinance, 2019)

Retail multinacional de moda: Es una empresa con locales en el extranjero similares a la sede principal que lleva los bienes y servicios de la industria de la moda desde la fabricación hasta los consumidores finales de forma internacional. (Autoría Propia, 2019)

Trabajador: Es aquella persona que tiene un trabajo retribuido. (Real Academia Española, 2019)

Influencia del branding de un retail multinacional de moda en la adquisición de productos en trabajadores: Es el poder que tiene un retail multinacional de la industria de la moda para influenciar la compra de bienes y/o servicios específicos en la sociedad al crear una relación y por ende un valor a través de su marca. (Autoría Propia, 2019)

Cliente: Es alguien que ha sido impactado por un producto, es el destinatario de un servicio o producto ofrecido por un suministrador, en una situación contractual, el cliente se denomina comprador. Pero a la vez puede ser consumidor final, usuario o beneficiario. (Jurán, 1993)

Millenials: Generación de personas nacidas entre 1981 y 1996, es decir entre las edades de 23 a 38 años a la actualidad. (Dimock, 2019)

Centennials: También conocidos como generación Z, es la generación de personas nacidas a partir de 1997 en adelante. (Dimock, 2019)

Influencers: Persona con poder de influencia en la percepción de otros para lograr que haga algo de forma diferente. Aplicada a marketing, un influencer es una persona quien apoya para que otras personas compren de una marca. (Dada, 2017) 
Logo: Señal, letra, símbolo o combinación de estos que representa e ilustra la marca de una empresa. (Doyle, 2011)

Slogan: Frase corta utilizada para publicitar o marketear un producto. (Doyle, 2011)

Packaging: Medio para proteger un producto publicitado. (Doyle, 2011)

\section{Objetivos e hipótesis}

\section{Objetivos.}

\section{Objetivo general}

Analizar la influencia del branding en la adquisición de productos de un retail multinacional de moda en trabajadores del distrito de Surco.

\section{Objetivos específicos}

Identificar la influencia del branding sensorial en la adquisición de productos de un retail multinacional de moda en trabajadores del distrito de Surco.

Determinar la influencia del branding digital en la adquisición de productos de un retail multinacional de moda en trabajadores del distrito de Surco.

Determinar la influencia del brand awareness en la adquisición de productos de un retail multinacional de moda en trabajadores del distrito de Surco.

\section{Hipótesis.}

\section{Hipótesis general}


$\mathrm{H}_{0}$ : El branding influye en la adquisición de productos de un retail multinacional de moda en trabajadores del distrito de Surco.

\section{Hipótesis específicas}

$\mathrm{H}_{1}$ : El branding sensorial influye en la adquisición de productos de un retail multinacional de moda en trabajadores del distrito de Surco.

$\mathrm{H}_{2}$ : El branding digital influye tanto positiva como negativamente en la adquisición de productos de un retail multinacional de moda en trabajadores del distrito de Surco.

$\mathrm{H}_{3}$ : El Brand awareness influye en la decisión de compra del consumidor en la adquisición de productos de un retail multinacional de moda en trabajadores del distrito de Surco.

\section{Delimitación}

La presente investigación abarca únicamente a trabajadores entre 20 a 39 años que residen en el distrito de Surco, ubicado en la provincia Lima y departamento del mismo nombre, quienes compren en retails de moda multinacional. Cubrirá un periodo de 9 meses, de noviembre 2019 a setiembre 2020 .

\section{Limitación}

Falta de actualización del registro de personas residiendo en Surco.

Falta de registro de personas económicamente activas por distrito.

Falta de un reporte de ingresos sólo por branding u otros métodos de marketing de los retails de moda multinacional. 


\section{Método}

\section{Tipo y diseño de investigación}

\section{Tipo de investigación.}

Esta investigación es de tipo correlacional causal, al tener como objetivo principal aumentar el conocimiento por sí mismo que beneficiará a la sociedad en un futuro. Corresponde a una investigación cuantitativa porque se basa en el uso de técnicas estadísticas para conocer aspectos de interés sobre la población que se estudia (Hueso \& Cascant, 2012).

\section{Diseño de investigación.}

Es no experimental ya que no se manipularán las variables; es decir, no se experimentará con ellas. Asimismo, es transversal pues se recogerán los datos en un solo punto del tiempo (Hernández, Fernández \& Baptista, 2010).

Se utilizará un diseño correlacional causal. Según Hernández, Fernández y Baptista (2014) en estos estudios la causalidad ya existe, pero es el investigador quien determina su dirección y establece cuál es la causa y cuál es el efecto. Para establecer un nexo causal, la variable independiente debe anteceder en tiempo a la dependiente, debe existir covariación entre ambas y la causalidad tiene que ser verosímil.

\section{Variables}

El tema a investigar cuenta con las siguientes dos variables, en la presente investigación se determinará el nivel de influencia que el branding ejerce en la adquisición de productos de un retail multinacional de moda en trabajadores del distrito de Surco.

Variable Independiente: Nivel de Influencia del Branding. 
Variable Dependiente: Adquisición de productos de un retail multinacional de moda en trabajadores.

Definida por los resultados obtenidos en la Escala del nivel de influencia del branding en la adquisición, cuyos valores son:

- Branding Sensorial

- Branding Digital

- Brand Awareness

\section{Variables Controladas}

- Deseabilidad Social:

Se controlará dado que la aplicación del instrumento se realizará en forma anónima, por lo que se presume que existen mayores probabilidades para que los participantes respondan de forma honesta.

- Fatiga y/o Cansancio Físico y Mental:

Será controlado debido a que se tendrá la libertad de escoger el momento de aplicación del instrumento, pudiéndose desarrollar durante las primeras horas de la jornada laboral y/o fines de semana, a juicio propio.

\section{Variable Extraña}

\section{Efecto Reactivo del Instrumento}

Consiste en que los participantes no necesariamente responden ante el instrumento como son en su vida cotidiana. 
Tabla 1: Operacionalización de la influencia del branding en la adquisición de productos de un retail multinacional de moda en trabajadores.

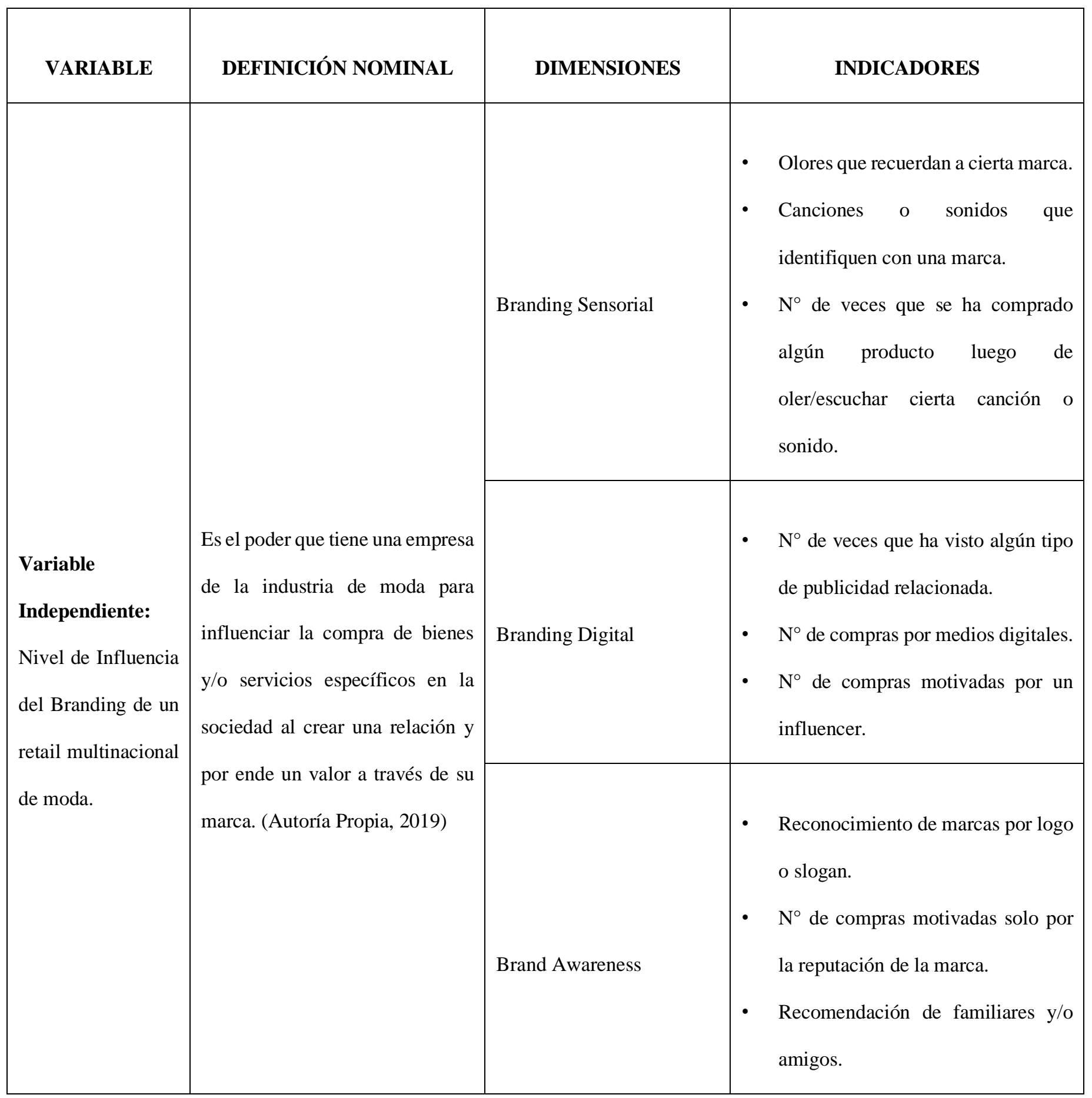




\begin{tabular}{|c|c|c|c|}
\hline & & & $\begin{array}{l}\text { - Nivel de influencia de la opinión de } \\
\text { terceros en su decisión de compra. }\end{array}$ \\
\hline $\begin{array}{l}\text { Variable } \\
\text { Dependiente: } \\
\text { Adquisición de } \\
\text { productos de un } \\
\text { retail multinacional } \\
\text { de moda. }\end{array}$ & $\begin{array}{l}\text { Es la acción de obtener o comprar } \\
\text { bienes y/o servicios, proceso en } \\
\text { el que se considera la demanda, } \\
\text { su preparación y procesamiento, } \\
\text { así como la recepción y } \\
\text { aprobación del pago dentro de la } \\
\text { industria de la moda. (Autoría } \\
\text { Propia, 2019) }\end{array}$ & $\begin{array}{l}\text { Asistencia a Retails de } \\
\text { moda multinacional }\end{array}$ & $\begin{array}{l}\text { - } \quad \text { Lugar de compras } \\
\text { - } \quad \text { Frecuencia de compras } \\
\text { Acompañantes y su influencia en las } \\
\text { compras. }\end{array}$ \\
\hline
\end{tabular}

Autor: Elaboración Propia

\section{Población}

La población de estudio estará conformada por 177,216 participantes de ambos sexos entre 20 a 39 años, quienes laboren en una institución en la ciudad de Lima y vivan en el distrito de Surco.

\section{Muestra}

El tipo de muestreo será probabilístico aleatorio, porque permite responder a los objetivos de la investigación con un nivel de confiabilidad de 95\%, varianza de 0.5 y un nivel de significación de $5 \%$.

La muestra estará constituida por 445 trabajadores de ambos sexos entre 20 a 39 años, quienes laboren en la ciudad de Lima y vivan en el distrito de Surco. 


\section{Criterios de inclusión:}

- Que estén laborando actualmente.

- Que realicen compras de retails de moda multinacional.

- Que participen voluntariamente.

\section{Criterios de exclusión:}

- Encontrarse en proceso de prácticas o jubilación.

- Que hayan respondido con errores los instrumentos (doble marca o ítems en blanco).

\section{Instrumentos de Investigación}

Nombre del instrumento: Escala del nivel de influencia del branding en la adquisición.

Autor(a): Linares Salazar, Claudia Paola.

Año: 2020

Procedencia: Lima (Perú)

Objetivo: Identificar el nivel de influencia del branding en la adquisición de productos de un retail multinacional de moda.

Dimensiones o áreas: Asistencia a retails de moda multinacional, Branding sensorial, branding digital y Brand awareness.

Aplicación o administración: Individual y Colectiva.

Dirigido a: Jóvenes y adultos.

$\mathrm{N}^{\circ}$ ítems: 13 preguntas.

Duración: 10 minutos.

Validez: Se determinará la validez del contenido a través de la consulta a tres jueces expertos. 
Confiabilidad: Se determinará la consistencia interna de los ítems a través del coeficiente Alfa de Cronbach.

\section{Procedimientos de recolección de datos}

\section{Coordinaciones Previas}

Será necesario el uso de medios tecnológicos como el acceso a internet y un ordenador o teléfono celular inteligente para la resolución de la encuesta.

La aplicación será virtual, por lo que las personas podrán responder en cualquier momento del día, se tendrán como fechas de recolección del 26 de julio 2020 al 01 de setiembre 2020.

\section{Presentación}

La presentación se realizará de la siguiente manera:

"Buenos días mi nombre es Claudia Linares Salazar y me encuentro realizando esta investigación con la finalidad de identificar el nivel de influencia del branding al momento de adquirir productos de un retail multinacional de moda; por lo que solicitamos su colaboración"

\section{Consentimiento informado}

Estimado(a):

Mi nombre es Claudia Linares Salazar, Bachiller en International Business de la Universidad San Ignacio de Loyola, y me encuentro realizando un proyecto de investigación para la obtención de mi título profesional.

El presente se hace llegar a usted con el propósito de explicarle en qué consiste esta investigación, se llama CONSENTIMIENTO INFORMADO. Léalo con cuidado y pregunte todo lo que desee antes de proceder. Sus preguntas van a ser contestadas. 
Mediante este se le invita a usted a participar en un estudio de investigación. El objetivo de este estudio es conocer el nivel de influencia del branding en la adquisición de productos de un retail multinacional de moda.

Su participación durará aproximadamente 10 minutos, es voluntaria, anónima y de carácter estrictamente confidencial.

Su decisión de participar o no, no afectará sus derechos. Con su decisión, usted no renuncia a sus derechos o a la potestad de hacer algún reclamo legal.

Si usted decide participar en este estudio, es libre de cambiar de opinión y retirarse en el momento que usted así lo quiera. Así mismo, se desea aclarar que usted no recibirá ningún pago por participar en el estudio, así como tampoco implicará algún costo para usted.

Si usted tiene alguna pregunta, comentario o preocupación con respecto al proyecto, por favor comuníquese con la investigadora responsable del proyecto al correo clinaress97@ gmail.com en el horario de lunes a sábado de $8 \mathrm{am}$ a $6 \mathrm{pm}$.

Se me ha invitado a participar del estudio sobre la influencia del branding de un retail multinacional de moda.

Al dar comienzo a la presente encuesta entiendo que he leído el presente consentimiento informado, comprendo las declaraciones contenidas en este y la necesidad de hacer constar mi consentimiento, por lo cual acepto libre y voluntariamente.

Ya que:

- He sido informado de los objetivos de la investigación. 
- Incluye información clara y precisa de la investigación, relativa al propósito del estudio, modalidad de participación, confidencialidad, anonimato, voluntariedad y derecho a retirarse del estudio en cualquier momento.

\section{Instrucciones}

Se administrará el instrumento de manera auto administrado: se le entrega el link de la escala a los respondientes y marcarán respecto a cada afirmación la categoría que mejor describe su respuesta.

\section{Plan de Análisis}

Para el análisis de los datos se utilizará el programa estadístico SPSS, con el cual se llevarán a cabo los análisis descriptivos e inferenciales como se detalla a continuación:

Se procederá en primer lugar a realizar el análisis descriptivo de las variables especificando las frecuencias obtenidas. Posteriormente para decidir el tipo de análisis Inferencial que se llevará a cabo, se aplicará el procedimiento de Kolmogorov-Smirnov (prueba no paramétrica), se examinará la distribución de los datos (simétrica o no), el tipo de muestreo utilizado y el coeficiente de variación. 


\section{Resultados}

Presentación de resultados

\section{Análisis Inferencial}

Análisis de regresión lineal simple para la hipótesis general

Tabla 2. Pruebas de normalidad de los residuos para la hipótesis general

\begin{tabular}{llll}
\hline & \multicolumn{2}{l}{ Kolmogorov-Smirnov ${ }^{\mathrm{a}}$} & \\
\cline { 2 - 4 } & Estadístico & $\mathrm{gl}$ & Sig. \\
\hline Standardized Residual & 0,067 & 445 & 0,000 \\
\hline
\end{tabular}

a. Corrección de significación de Lilliefors

Autor: Elaboración Propia

En la tabla de la prueba de normalidad se aprecia un valor inferior al nivel de significancia de 0,05 (Sig.<0,05). Lo cual indica que no se cumple la distribución normal de los residuos. 
Gráfico 1: Grafico de dispersión de las variables

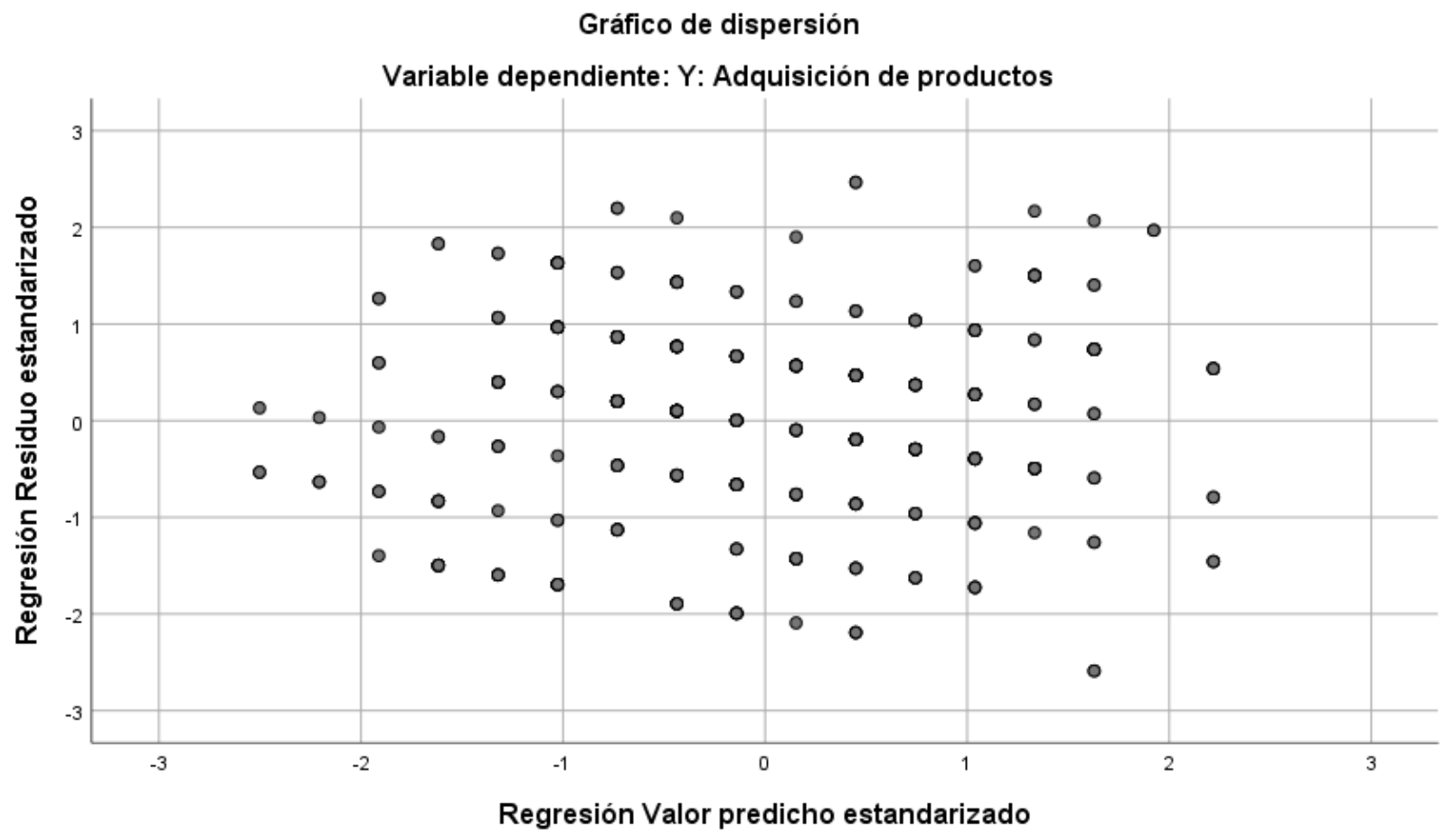

Autor: Elaboración Propia

En el gráfico de dispersión de los residuos estandarizados, se aprecia que los datos no muestran un patrón definido, de manera que se asume que hay homocedasticidad.

Tabla 3. Resumen del modelo de la hipótesis general

\section{Error estándar}

R cuadrado de la Durbin-

Modelo R R cuadrado ajustado estimación Watson

\begin{tabular}{llllll}
\hline 1 & 0,319 & 0,102 & 0,100 & 1,503 & 1,809
\end{tabular}

a. Predictores: (Constante), X: Branding

b. Variable dependiente: Y: Adquisición de productos 
En la tabla se aprecia que el coeficiente $\mathrm{R}$ expresa un valor de 0,319 , lo cual indica que hay poca linealidad. Por otro lado, el coeficiente del R cuadrado expresa un valor de 0,102 ; lo cual indica que la variable Branding explica en 10,2\% a la variable Adquisición. A su vez, el coeficiente de Durbin-Watson arrojó un valor de 1,809, lo cual al estar dentro de los valores de 1,5 a 2,5, lo que indica que no hay autocorrelación de los residuos. Este valor indica que sí cumple con el supuesto de no autocorrelación.

Tabla 4. ANOVA

\begin{tabular}{lcccccc}
\hline \multicolumn{2}{l}{ Suma de } & \multicolumn{3}{l}{ Media } \\
\multicolumn{2}{l}{ Modelo } & cuadrados & $\mathrm{gl}$ & cuadrática & $\mathrm{F}$ & Sig. \\
\hline 1 & Regresión & 113,700 & 1 & 113,700 & 50,355 & 0,000 \\
& Residuo & 1000,278 & 443 & 2,258 & & \\
& Total & 1113,978 & 444 & & & \\
\end{tabular}

a. Variable dependiente: Y: Adquisición de productos

b. Predictores: (Constante), X: Branding

La significancia de la prueba de Anova indica un valor de 0,000; lo cual es inferior al nivel de significancia 0,05 (Sig.<0,05). Esto nos indica que el modelo de regresión lineal simple para la hipótesis general si es factible para su utilización.

\section{Hipótesis general}

H1: El branding influye en la adquisición de productos de un retail multinacional de moda en trabajadores del distrito de Surco. 
H0: El branding no influye en la adquisición de productos de un retail multinacional de moda en trabajadores del distrito de Surco.

Tabla 5. Coeficientes

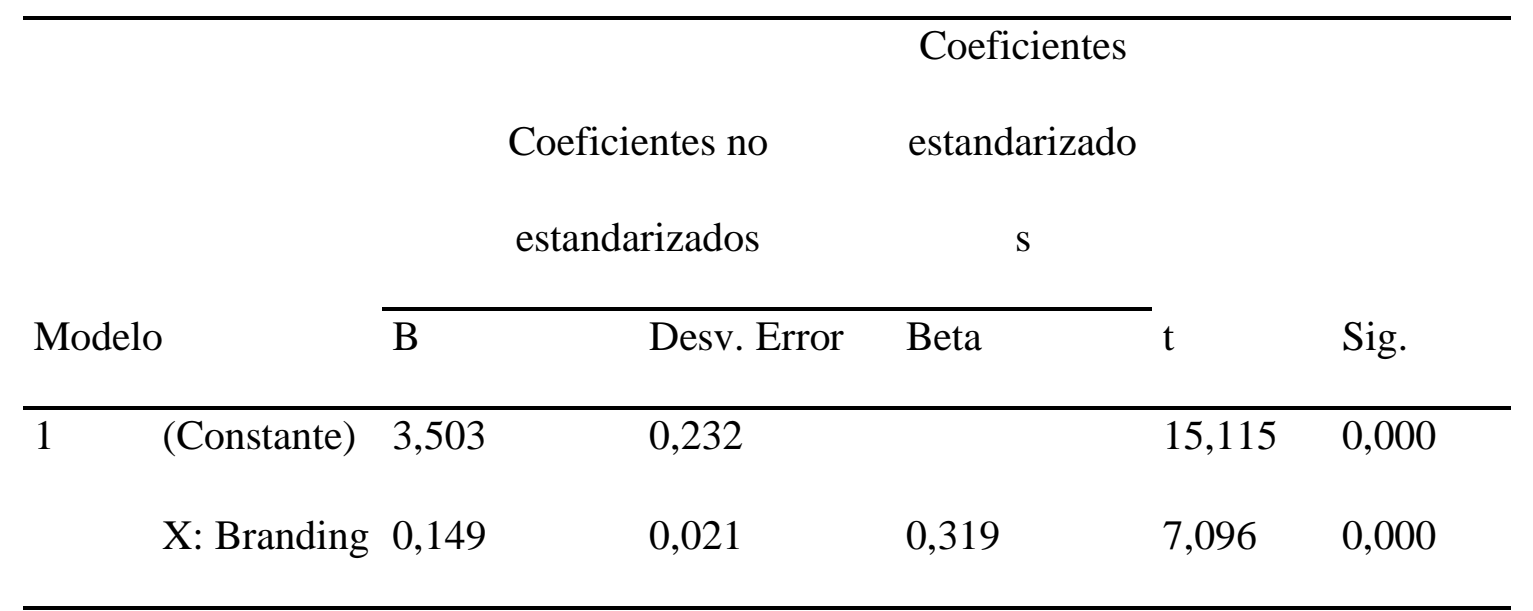

a. Variable dependiente: Y: Adquisición de productos

b. Predictores: (Constante), X: Branding

El T de Student dio un resultado de significancia inferior al nivel de significancia de 0,05 (Sig. $<0,05)$. Lo que nos indica que se rechaza la hipótesis nula y por tanto el branding si influye en la adquisición de productos de un retail multinacional de moda en trabajadores del distrito de Surco. De esta manera la ecuación de regresión lineal queda conformada por lo siguiente: $\mathrm{Y}=3,503+0,149 \mathrm{X}$ 
Análisis de regresión lineal simple para la hipótesis especifica:

Branding Sensorial

Tabla 6. Pruebas de normalidad

\begin{tabular}{lllc}
\hline & \multicolumn{2}{l}{ Kolmogorov-Smirnov ${ }^{\mathrm{a}}$} \\
\cline { 2 - 4 } & Estadístico & $\mathrm{gl}$ & $\mathrm{Sig}$. \\
\hline Standardized Residual & 0,095 & 445 & 0,000 \\
\hline
\end{tabular}

a. Corrección de significación de Lilliefors

En la tabla de la prueba de normalidad se aprecia un valor inferior al nivel de significancia de 0,05 (Sig.<0,05). Lo cual indica que no se cumple la distribución normal de los residuos.

Gráfico 2: Grafico de dispersión de las variables

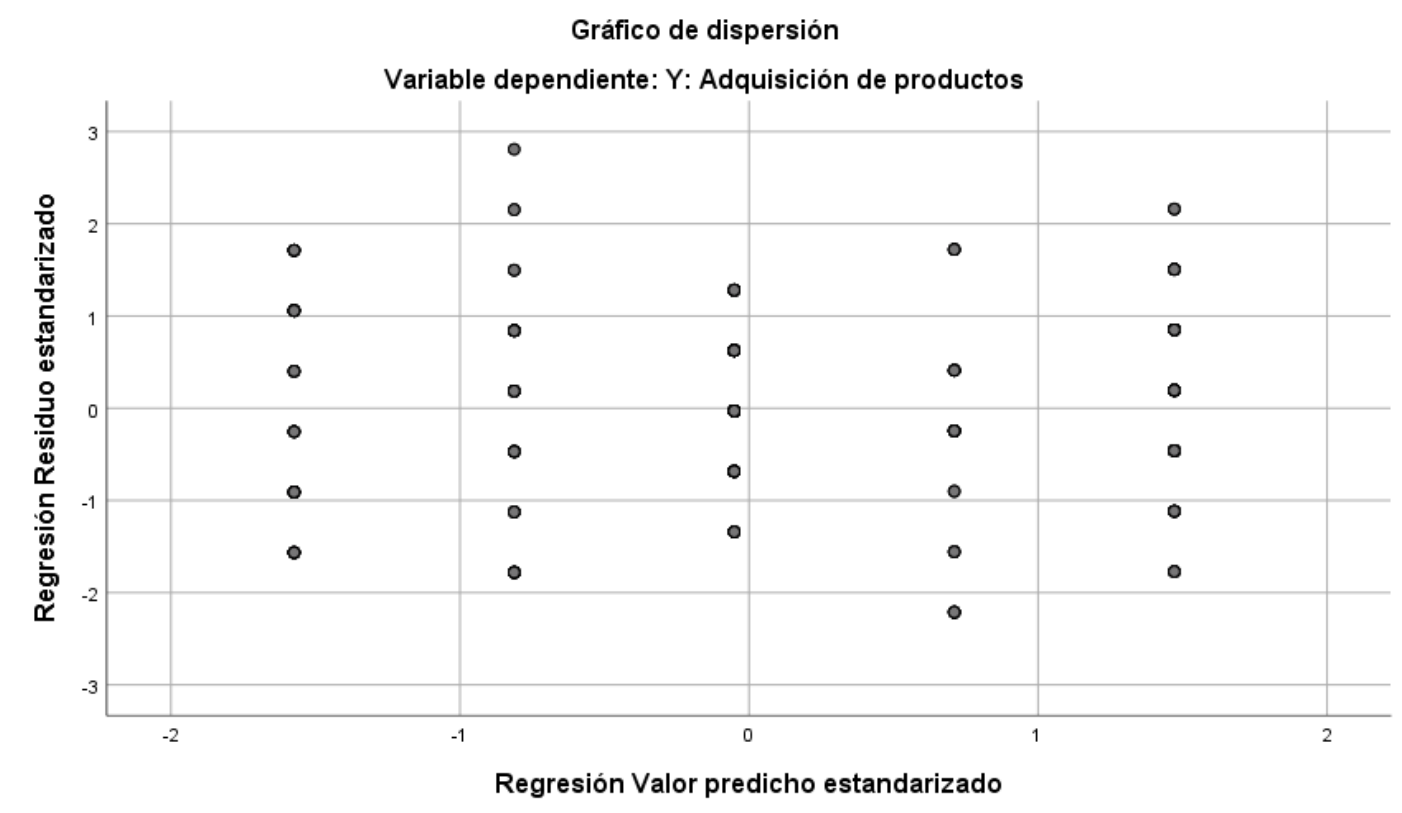

Autor: Elaboración Propia

En el gráfico de dispersión de los residuos estandarizados, se aprecia que los datos no muestran un patrón definido, de manera que se asume que hay homocedasticidad. 
Tabla 7. Resumen del modelo

\begin{tabular}{llllll}
\hline & & & \multicolumn{3}{c}{ Error estándar } \\
& & & & \\
& & & & cuadrado de & la Durbin- \\
Modelo & $\mathrm{R}$ & R cuadrado & ajustado & estimación & Watson \\
\hline 1 & 0,273 & 0,074 & 0,072 & 1,526 & 1,816 \\
\hline
\end{tabular}

a. Predictores: (Constante), x3: Brand Sensorial

b. Variable dependiente: Y: Adquisición de productos

En la tabla se aprecia que el coeficiente $\mathrm{R}$ expresa un valor de 0,273 , lo cual indica que hay poca linealidad. Por otro lado, el coeficiente del R cuadrado expresa un valor de 0,074 ; lo cual indica que la variable Branding Sensorial explica en 7,4\% a la variable Adquisición. A su vez, el coeficiente de Durbin-Watson arrojó un valor de 1,816, lo cual al estar dentro de los valores de 1,5 a 2,5, lo que indica que no hay autocorrelación de los residuos. Este valor indica que sí cumple con el supuesto de no autocorrelación.

Tabla 8. ANOVA

\begin{tabular}{lllllll}
\hline \multicolumn{2}{l}{ Modelo } & \multicolumn{1}{l}{ Suma } & de & Media & & \\
& cuadrados & gl & cuadrática & F & Sig. \\
\hline 1 & Regresión & 82,891 & 1 & 82,891 & 35,614 & 0,000 \\
& Residuo & 1031,086 & 443 & 2,328 & & \\
& Total & 1113,978 & 444 & & & \\
\hline
\end{tabular}

a. Variable dependiente: Y: Adquisición de productos

b. Predictores: (Constante), x3: Brand Sensorial 
La significancia de la prueba de Anova indica un valor de 0,000; lo cual es inferior al nivel de significancia 0,05 (Sig.<0,05). Esto nos indica que el modelo de regresión lineal simple para la hipótesis general si es factible para su utilización.

\section{Hipótesis especifica: Branding Sensorial}

H1: El branding sensorial influye en la adquisición de productos de un retail multinacional de moda en trabajadores del distrito de Surco.

H0: El branding sensorial no influye en la adquisición de productos de un retail multinacional de moda en trabajadores del distrito de Surco.

Tabla 9. Coeficientes

\begin{tabular}{|c|c|c|c|c|c|c|}
\hline & \multirow[b]{4}{*}{ Modelo } & & & \multirow{3}{*}{$\begin{array}{l}\text { Coeficientes } \\
\text { estandarizad } \\
\text { os }\end{array}$} & \multirow[b]{4}{*}{$\mathrm{t}$} & \multirow[b]{4}{*}{ Sig. } \\
\hline & & \multirow{2}{*}{\multicolumn{2}{|c|}{$\begin{array}{l}\text { Coeficientes no } \\
\text { estandarizados }\end{array}$}} & & & \\
\hline & & & & & & \\
\hline & & B & Desv. Error & Beta & & \\
\hline 1 & (Constante) & 4,387 & 0,135 & & 32,505 & 0,000 \\
\hline & x3: Brand & 0,329 & 0,055 & 0,273 & 5,968 & 0,000 \\
\hline & Sensorial & & & & & \\
\hline
\end{tabular}

a. Variable dependiente: Y: Adquisición de productos

El T de Student dio un resultado de significancia inferior al nivel de significancia de 0,05 (Sig. <0,05). Lo que nos indica que se rechaza la hipótesis nula y por tanto el branding sensorial si influye en la adquisición de productos de un retail multinacional de moda en trabajadores 
del distrito de Surco. De esta manera la ecuación de regresión lineal queda conformada por lo siguiente: $\mathrm{Y}=4,387+0,329 \mathrm{X}$

Análisis de regresión lineal simple para la hipótesis especifica:

\section{Branding Digital}

Tabla 10. Pruebas de normalidad

\begin{tabular}{cccc}
\hline & \multicolumn{3}{c}{ Kolmogorov-Smirnov $^{\mathrm{a}}$} \\
\cline { 2 - 4 } & Estadístico & $\mathrm{gl}$ & Sig. \\
\hline Standardized Residual & 0,069 & 445 & 0,000 \\
\hline
\end{tabular}

a. Corrección de significación de Lilliefors

En la tabla de la prueba de normalidad se aprecia un valor inferior al nivel de significancia de 0,05 (Sig.<0,05). Lo cual indica que no se cumple la distribución normal de los residuos.

Gráfico 3: Grafico de dispersión de las variables

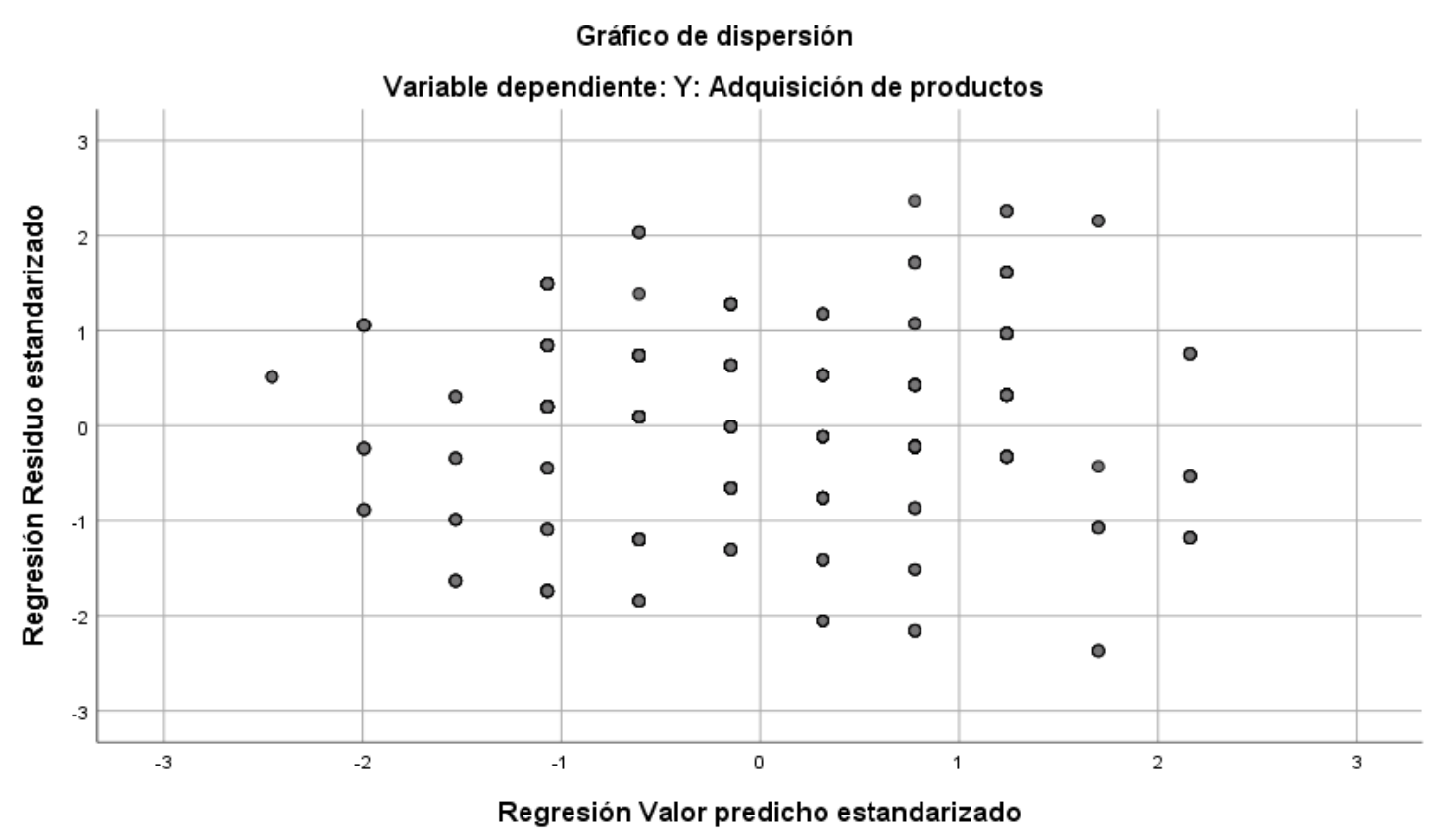

Autor: Elaboración Propia 
En el gráfico de dispersión de los residuos estandarizados, se aprecia que los datos no muestran un patrón definido, de manera que se asume que hay homocedasticidad.

Tabla 11. Resumen del modelo

\begin{tabular}{llllll}
\hline & & & \multicolumn{3}{c}{ Error estándar } \\
& & & & & \\
& & & & \\
Modelo cuadrado de & la Durbin- \\
& $\mathrm{R}$ & R cuadrado & ajustado & estimación & Watson \\
\hline 1 & 0,222 & 0,049 & 0,047 & 1,546 & 1,854 \\
\hline
\end{tabular}
a. Predictores: (Constante), x2: Branding Digital
b. Variable dependiente: Y: Adquisición de productos

En la tabla se aprecia que el coeficiente R expresa un valor de 0,222 , lo cual indica que hay poca linealidad. Por otro lado, el coeficiente del R cuadrado expresa un valor de 0,049 ; lo cual indica que la variable Branding Digital explica en 4,9\% a la variable Adquisición. A su vez, el coeficiente de Durbin-Watson arrojó un valor de 1,854, lo cual al estar dentro de los valores de 1,5 a 2,5, lo que indica que no hay autocorrelación de los residuos. Este valor indica que sí cumple con el supuesto de no autocorrelación.

Tabla 12. ANOVA

\begin{tabular}{lllllll}
\hline \multicolumn{2}{l}{ Modelo } & Suma & de & Media & & \\
& cuadrados & gl & cuadrática & F & Sig. \\
\hline 1 & Regresión & 54,700 & 1 & 54,700 & 22,876 & 0,000 \\
& Residuo & 1059,278 & 443 & 2,391 & & \\
& Total & 1113,978 & 444 & & & \\
\hline
\end{tabular}

a. Variable dependiente: Y: Adquisición de productos 
b. Predictores: (Constante), x2: Branding Digital

La significancia de la prueba de Anova indica un valor de 0,000; lo cual es inferior al nivel de significancia 0,05 (Sig.<0,05). Esto nos indica que el modelo de regresión lineal simple para la hipótesis general si es factible para su utilización.

\section{Hipótesis especifica: Branding Digital}

H1: El branding digital influye tanto positiva como negativamente en la adquisición de productos de un retail multinacional de moda en trabajadores del distrito de Surco.

H0: El branding digital no influye ni positiva ni negativamente en la adquisición de productos de un retail multinacional de moda en trabajadores del distrito de Surco.

Tabla 13. Coeficientes

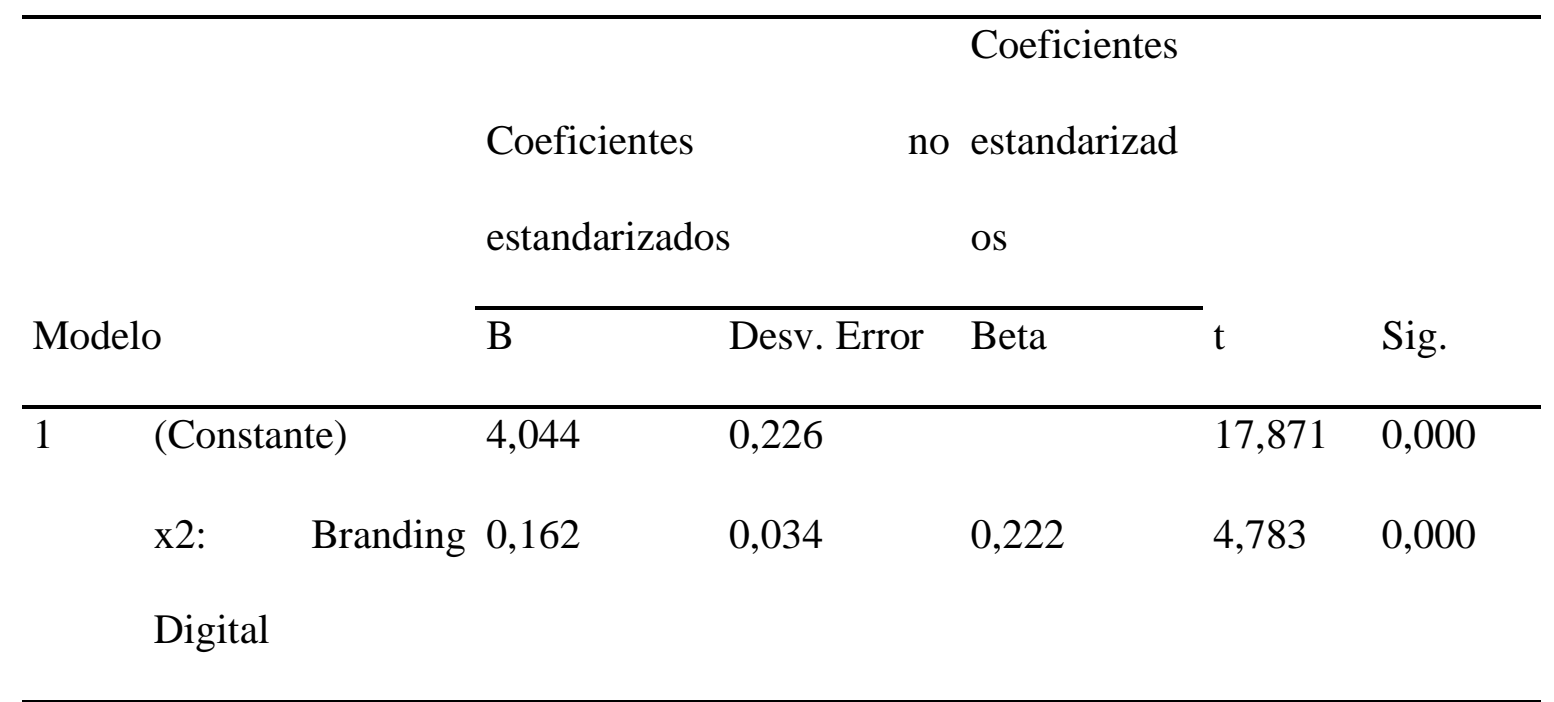

a. Variable dependiente: Y: Adquisición de productos

El $\mathrm{T}$ de Student dio un resultado de significancia inferior al nivel de significancia de 0,05 (Sig. <0,05). Lo que nos indica que se rechaza la hipótesis nula y por tanto el branding digital si influye en la adquisición de productos de un retail multinacional de moda en trabajadores 
del distrito de Surco tanto de forma positiva como negativa. De esta manera la ecuación de regresión lineal queda conformada por lo siguiente: $Y=4,044+0,162 X$

Análisis de regresión lineal simple para la hipótesis especifica: Brand Awareness

Tabla 14. Pruebas de normalidad

\begin{tabular}{llll}
\hline & \multicolumn{2}{l}{ Kolmogorov-Smirnov } \\
\cline { 2 - 4 } & Estadístico & gl & Sig. \\
\hline Standardized Residual & 0,097 & 445 & 0,000 \\
\hline
\end{tabular}

a. Corrección de significación de Lilliefors

En la tabla de la prueba de normalidad se aprecia un valor inferior al nivel de significancia de 0,05 (Sig.<0,05). Lo cual indica que no se cumple la distribución normal de los residuos. 
Gráfico 4: Grafico de dispersión de las variables

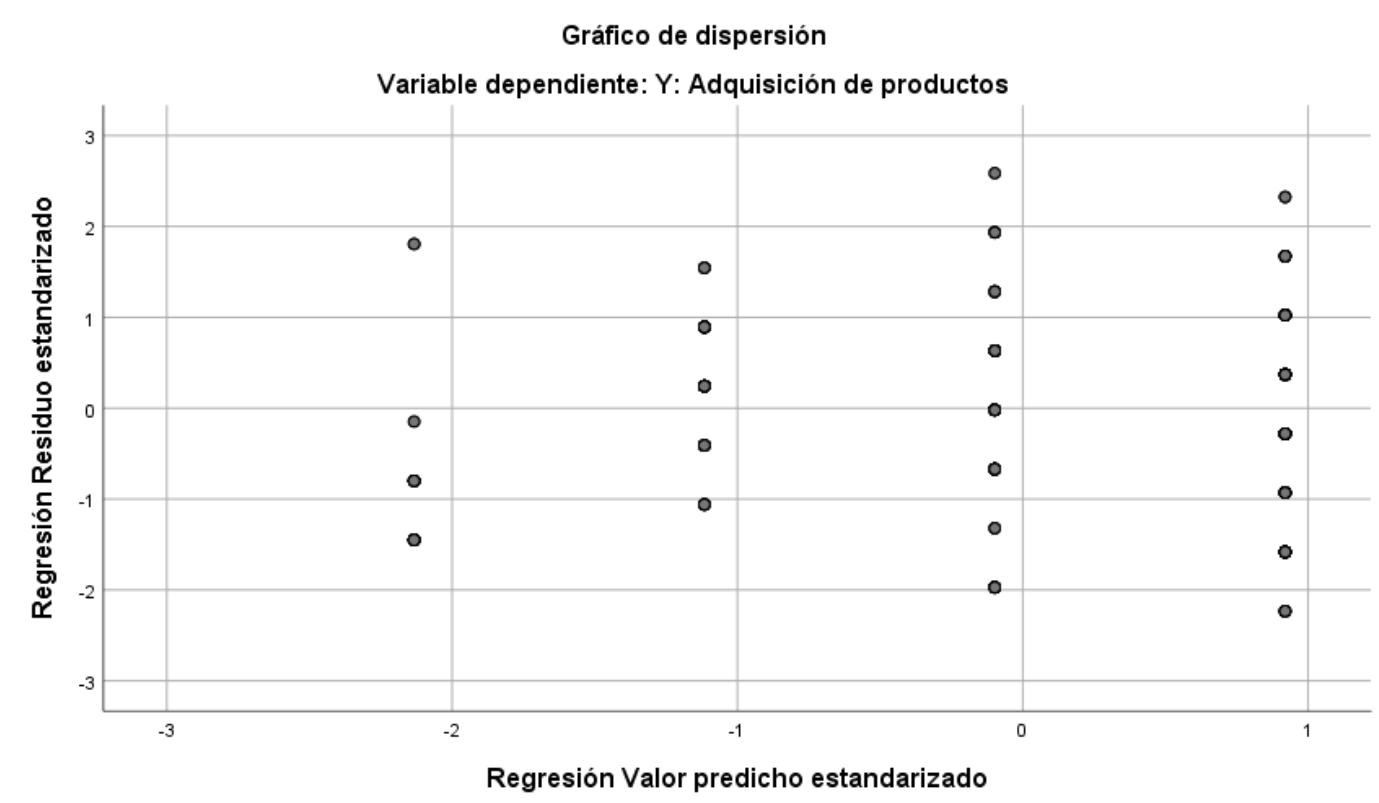

Autor:

Elaboración Propia

En el gráfico de dispersión de los residuos estandarizados, se aprecia que los datos no muestran un patrón definido, de manera que se asume que hay homocedasticidad.

Tabla 15. Resumen del modelo

\begin{tabular}{llllll}
\hline & & & R cuadrado & Error estándar & \\
Modelo & $\mathrm{R}$ & R cuadrado & ajustado & de la estimación & Durbin-Watson \\
\hline 1 & 0,249 & 0,062 & 0,060 & 1,536 & 1,833
\end{tabular}

a. Predictores: (Constante), x1: Branding Awereness

b. Variable dependiente: Y: Adquisición de productos

En la tabla se aprecia que el coeficiente R expresa un valor de 0,249 , lo cual indica que hay poca linealidad. Por otro lado, el coeficiente del R cuadrado expresa un valor de 0,062 ; lo cual indica que la variable Brand Awareness explica en 6,2\% a la variable Adquisición. A su vez, el coeficiente de Durbin-Watson arrojó un valor de 1,833, lo cual al estar dentro de los valores 
de 1,5 a 2,5, lo que indica que no hay autocorrelación de los residuos. Este valor indica que sí cumple con el supuesto de no autocorrelación.

Tabla 16. ANOVA

\begin{tabular}{|c|c|c|c|c|c|c|}
\hline & & Suma de & & Media & & \\
\hline & Modelo & cuadrados & $\mathrm{gl}$ & cuadrática & $\mathrm{F}$ & Sig. \\
\hline \multirow[t]{3}{*}{1} & Regresión & 69,066 & 1 & 69,066 & 29,281 & 0,000 \\
\hline & Residuo & 1044,911 & 443 & 2,359 & & \\
\hline & Total & 1113,978 & 444 & & & \\
\hline
\end{tabular}

a. Variable dependiente: Y: Adquisición de productos

b. Predictores: (Constante), x1: Branding Awareness

La significancia de la prueba de Anova indica un valor de 0,000; lo cual es inferior al nivel de significancia 0,05 (Sig.<0,05). Esto nos indica que el modelo de regresión lineal simple para la hipótesis general si es factible para su utilización.

\section{Hipótesis especifica: Branding Awareness}

H1: El Brand awareness influye en la decisión de compra del consumidor en la adquisición de productos de un retail multinacional de moda en trabajadores del distrito de Surco.

H0: El Brand awareness no influye en la decisión de compra del consumidor en la adquisición de productos de un retail multinacional de moda en trabajadores del distrito de Surco. 
Tabla 17. Coeficientes

\begin{tabular}{|c|c|c|c|c|c|c|}
\hline & & \multicolumn{2}{|c|}{$\begin{array}{l}\text { Coeficientes no } \\
\text { estandarizados }\end{array}$} & \multirow{2}{*}{$\begin{array}{l}\text { Coeficientes } \\
\text { estandarizados } \\
\text { Beta }\end{array}$} & \multirow{2}{*}{ t } & \multirow[b]{2}{*}{ Sig. } \\
\hline \multicolumn{2}{|c|}{ Modelo } & B & Desv. Error & & & \\
\hline \multirow[t]{4}{*}{1} & (Constante) & 4,226 & 0,172 & & 24,6 & 0,000 \\
\hline & & & & & 14 & \\
\hline & $\mathrm{x} 1$ : Brand & 0,401 & 0,074 & 0,249 & 5,41 & 0,000 \\
\hline & Awereness & & & & 1 & \\
\hline
\end{tabular}

a. Variable dependiente: Y: Adquisición de productos

El T de Student dio un resultado de significancia inferior al nivel de significancia de 0,05 (Sig. $<0,05)$. Lo que nos indica que se rechaza la hipótesis nula y por tanto el brand awareness si influye en la adquisición de productos de un retail multinacional de moda en trabajadores del distrito de Surco. De esta manera la ecuación de regresión lineal queda conformada por lo siguiente: $\mathrm{Y}=4,226+$ $0,401 X$

Tabla 18. Estadísticas de residuos

Desv.

Mínimo Máximo Media Desviación N

\begin{tabular}{llllll}
\hline Valor pronosticado & 4,21 & 5,83 & 5,07 & 0,351 & 445 \\
Residuo & $-3,664$ & 3,660 & 0,000 & 1,545 & 445 \\
Desv. Valor & $-2,455$ & 2,162 & 0,000 & 1,000 & 445 \\
pronosticado & & & & & \\
Desv. Residuo & $-2,370$ & 2,367 & 0,000 & 0,999 & 445
\end{tabular}

a. Variable dependiente: Y: Adquisición de productos 


\section{Análisis Descriptivo}

En la siguiente tabla $\mathrm{N}^{\circ} 19$ y Anexo $\mathrm{N}^{\circ} 2$ se observa que del $100 \%$ de los encuestados, la mayoría son de sexo femenino. Lo cual es el $65 \%$, mientras que el restante $34,4 \%$ son de sexo masculino.

Tabla 19. Sexo de los trabajadores del distrito de Surco, 2020

\begin{tabular}{llllll}
\hline & & & Porcentaje & Porcentaje \\
& & Frecuencia & Porcentaje & válido & acumulado \\
\hline Válido & Femenino & 292 & 65,6 & 65,6 & 65,6 \\
& Hombre & 153 & 34,4 & 34,4 & 100,0 \\
& Total & 445 & 100,0 & 100,0 & \\
\hline
\end{tabular}

En la siguiente tabla $\mathrm{N}^{\circ} 21$ y figura $\mathrm{N}^{\circ} 1$ se observa que, principalmente, el $32,4 \%$ de los encuestados, compran cada dos o tres meses ropa, calzados y/o accesorios. Le sigue el 25,2\% que realiza sus compras cada semestre. Por otra parte, el 20,9\% lo realiza cada mes.

Tabla 21. Frecuencia de compras de ropa, calzado y/o accesorios de encuestados, 2020

\begin{tabular}{llllll}
\hline & & & Porcentaje & Porcentaje \\
& & Frecuencia & Porcentaje & válido & acumulado \\
\hline Válido & Cada mes & 93 & 20,9 & 20,9 & 20,9 \\
& Cada dos - tres meses & 144 & 32,4 & 32,4 & 53,3 \\
& Cada semestre & 112 & 25,2 & 25,2 & 78,4 \\
& Una vez al año & 16 & 3,6 & 3,6 & 82,0 \\
& Cada cambio de estacion & 80 & 18,0 & 18,0 & 100,0 \\
& & & & \\
& & & 100,0 & 100,0 & \\
\hline
\end{tabular}

Autor: Elaboración Propia 
Figura 1. Frecuencia de compra de los encuestados, 2020

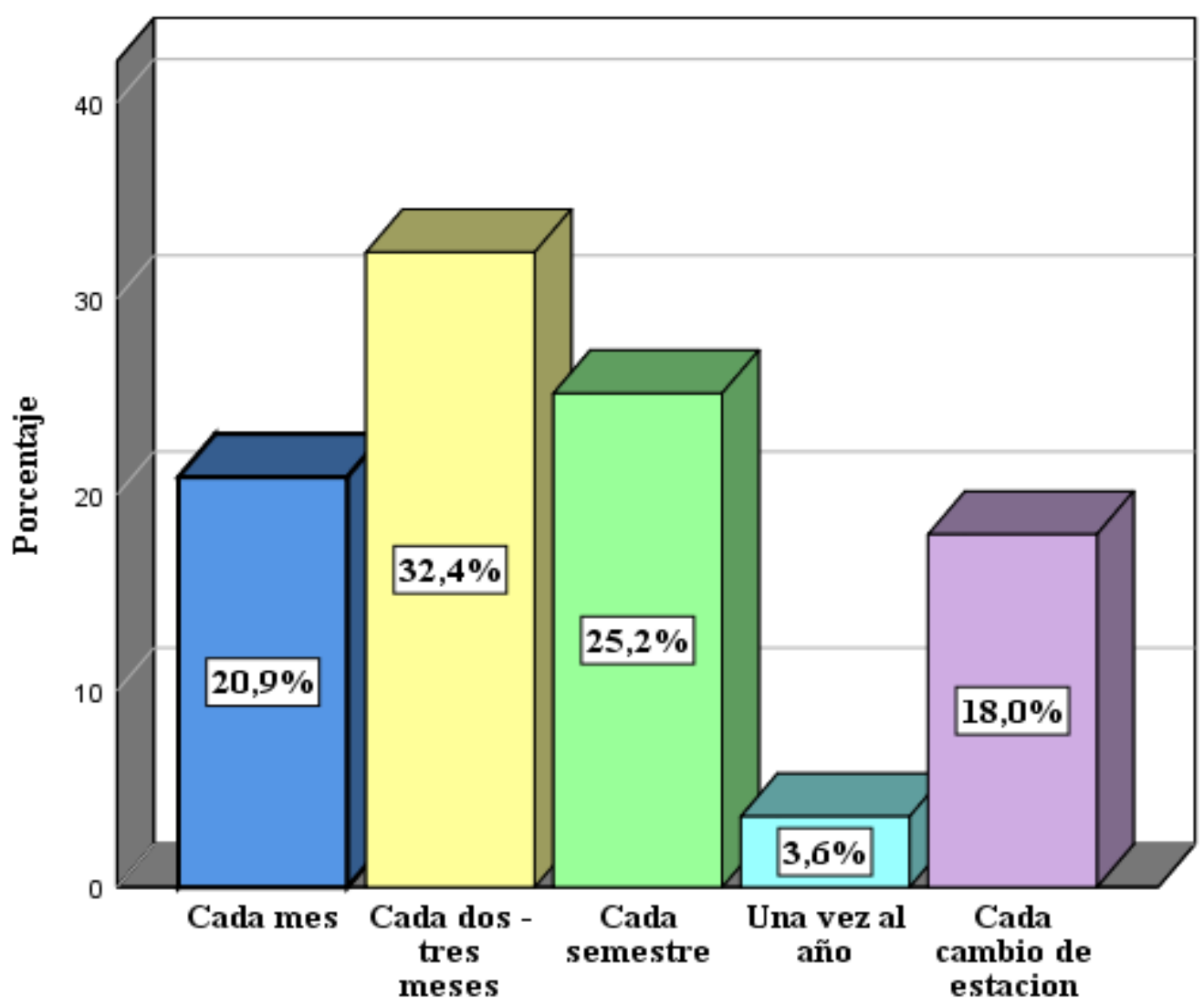

En base a las siguientes opciones, ¿Con que frecuencia realizas compras de ropa, calzado y/o accesorios?

Autor: Elaboración Propia

En la siguiente tabla $\mathrm{N}^{\circ} 22$ y figura $\mathrm{N}^{\circ} 2$ se observa que el $29,7 \%$ de los consumidores asisten en su mayoría de compras de moda acompañados de su familia, posteriormente el 27,4\% asiste solo, seguido del 22,7\% acompañado por amigos. 
Tabla 22. Acompañante de los encuestados en las compras, 2020

\begin{tabular}{llllll}
\hline & & & Porcentaje & Porcentaje \\
& & Frecuencia & Porcentaje & válido & acumulado \\
\hline Válido & Solo & 122 & 27,4 & 27,4 & 27,4 \\
& Con familia & 132 & 29,7 & 29,7 & 57,1 \\
& Con amigos & 101 & 22,7 & 22,7 & 79,8 \\
Con mi pareja & 81 & 18,2 & 18,2 & 98,0 \\
Con mis hijos & 9 & 2,0 & 2,0 & 100,0 \\
Total & 445 & 100,0 & 100,0 & \\
\hline
\end{tabular}

Autor: Elaboración Propia

Figura 2. Acompañante de los encuestados en las compras, 2020

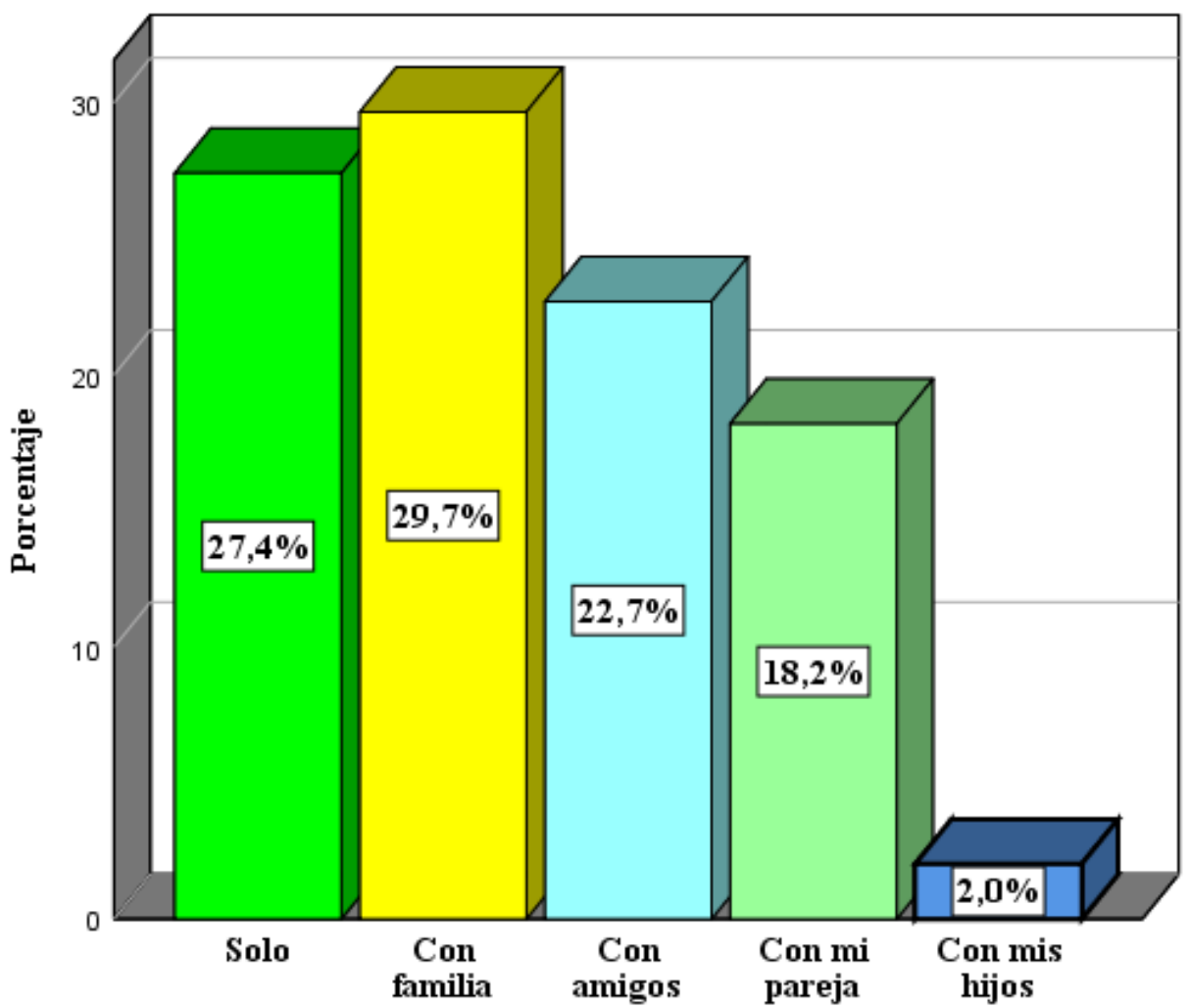

Cuando vas a comprar moda, ¿sueles ir solo o acompañado? En caso vayas acompañado, ¿con quién vas mayormente?

Autor: Elaboración Propia 
En la siguiente tabla $\mathrm{N}^{\circ} 23$ y figura $\mathrm{N}^{\circ} 3$ se observa que el $44 \%$ de los encuestados declara tener poca influencia de otros en sus compras de moda, mientras el $23,8 \%$ declara que la influencia que recibe de otros es mucha.

Tabla 23. Influencia de otros en las compras de los encuestados, 2020

\begin{tabular}{llllll}
\hline & & & & Porcentaje & Porcentaje \\
& & Frecuencia & Porcentaje & válido & acumulado \\
\hline Válido & Bastante & 26 & 5,8 & 5,8 & 5,8 \\
& Mucho & 104 & 23,4 & 23,4 & 29,2 \\
& Poco & 196 & 44,0 & 44,0 & 73,3 \\
& Muy Poco & 65 & 14,6 & 14,6 & 87,9 \\
& Nada & 54 & 12,1 & 12,1 & 100,0 \\
Total & 445 & 100,0 & 100,0 & \\
\hline
\end{tabular}

Autor: Elaboración Propia 
Figura 3. Influencia de otros en las compras de los encuestados, 2020

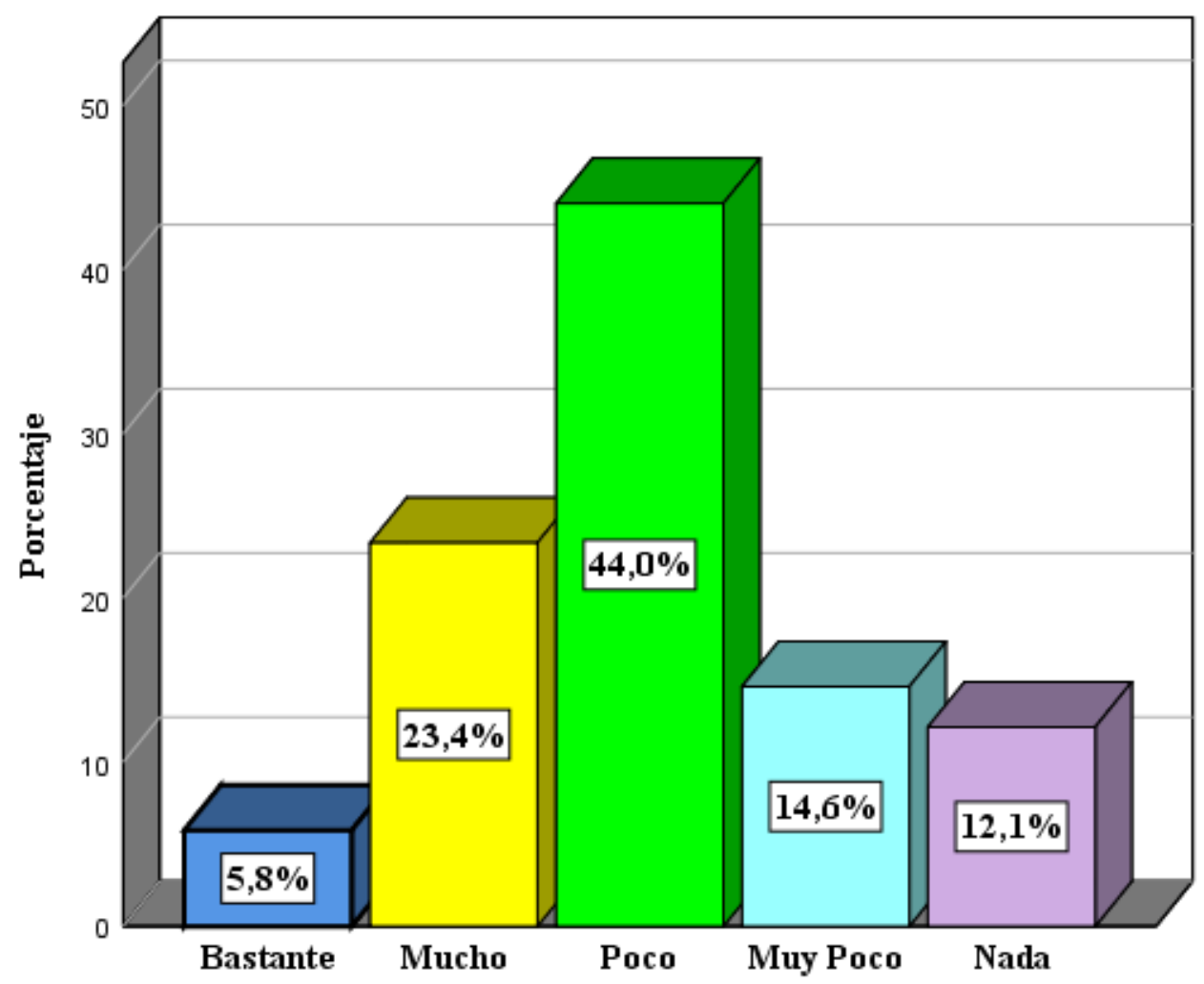

¿Qué tanto influyen otros en tu decisión de compra de moda?

Autor: Elaboración Propia

En la siguiente tabla $\mathrm{N}^{\circ} 24$ y figura $\mathrm{N}^{\circ} 4$ se observa que el $94,4 \%$ de los encuestados logró recordar alguna marca, mientras que solo el 5,6\% no recuerda ninguna marca.

Tabla 24. Capacidad de los encuestados de recordar una marca de moda, 2020

\begin{tabular}{llllll}
\hline & & & & Porcentaje & Porcentaje \\
& & Frecuencia & Porcentaje & válido & acumulado \\
\hline Válido & Si Recuerda alguna marca & 420 & 94,4 & 94,4 & 94,4 \\
& No recuerda ninguna & 25 & 5,6 & 5,6 & 100,0 \\
& marca & & & & \\
& & & & & \\
& Total & 445 & 100,0 & 100,0 & \\
\hline
\end{tabular}

Autor: Elaboración Propia 
Figura 4. Capacidad de los encuestados de recordar una marca de moda, 2020

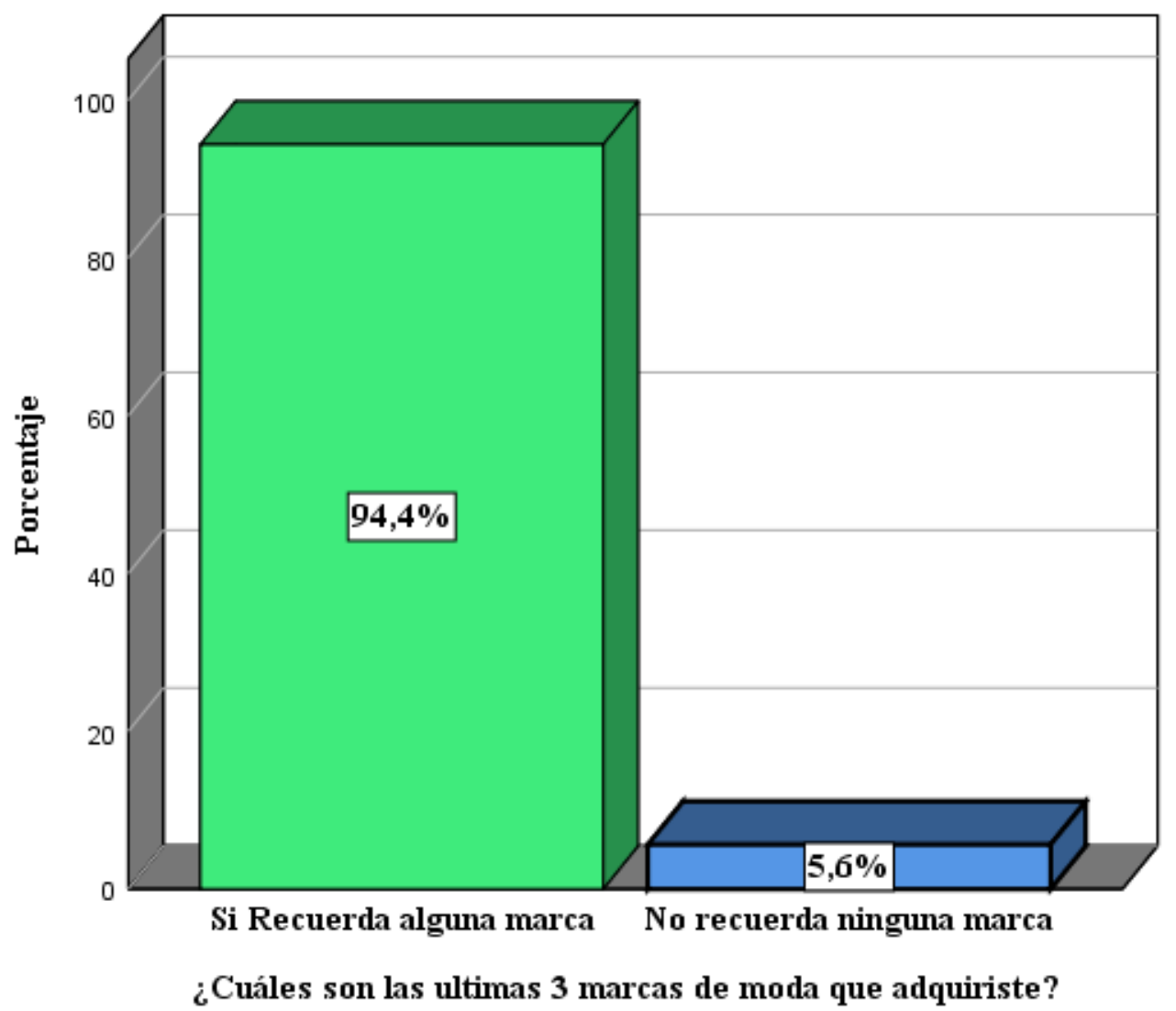

Autor: Elaboración Propia

En la siguiente tabla $\mathrm{N}^{\circ} 25$ y figura $\mathrm{N}^{\circ} 5$ se observa que el $91,5 \%$ de los encuestados recuerda el logo y/o slogan de alguna marca que haya vestido anteriormente, mientras que solo el 8,5\% no recuerda ninguna marca que haya vestido o adquirido.

Tabla 25. Recordar logo y/o slogan de una marca, 2020

\begin{tabular}{llllll}
\hline & & Frecuencia & Porcentaje & Porcentaje válido & Porcentaje acumulado \\
\hline Válido & $\mathrm{Si}$ & 407 & 91,5 & 91,5 & 91,5 \\
& $\mathrm{No}$ & 38 & 8,5 & 8,5 & 100,0 \\
& Total & 445 & 100,0 & 100,0 & \\
\hline
\end{tabular}

Autor: Elaboración Propia 
Figura 5. Recordar logo y/o slogan de una marca, 2020

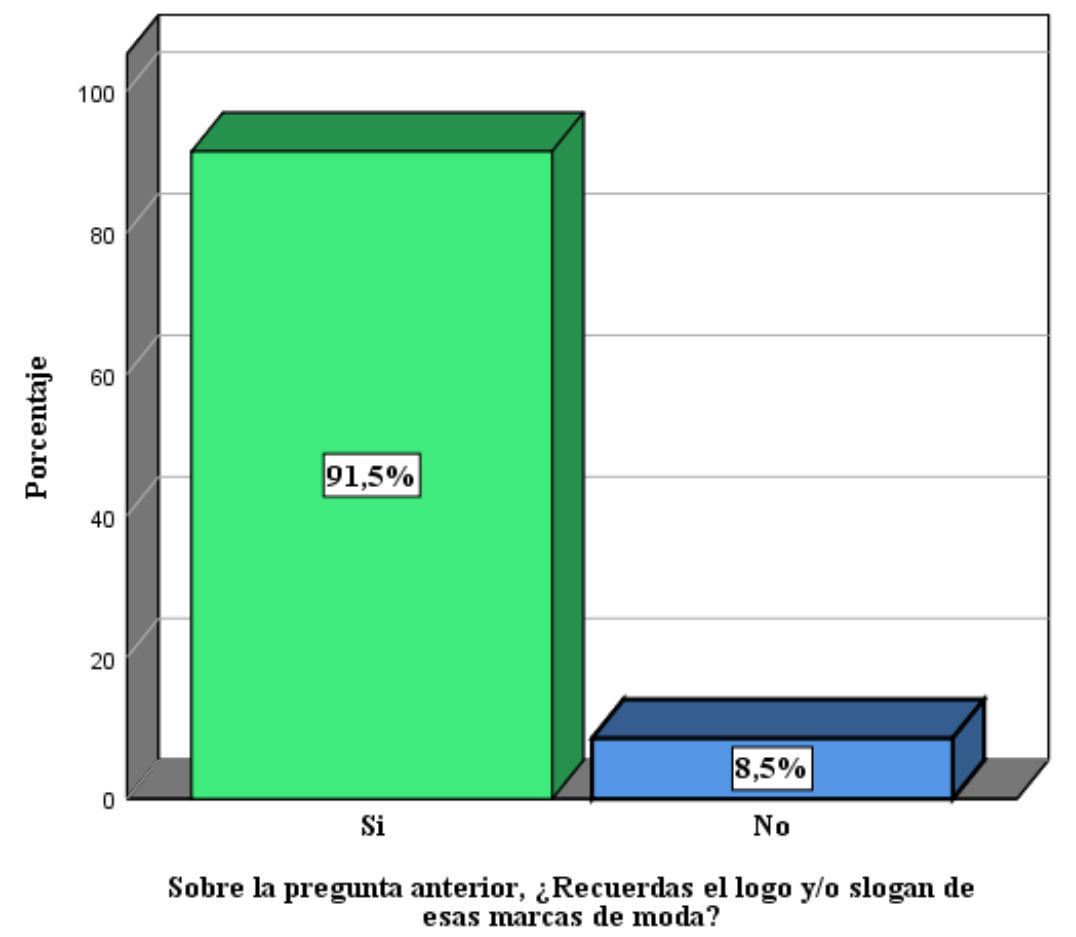

Autor: Elaboración Propia

En la siguiente tabla $\mathrm{N}^{\circ} 26$ y figura $\mathrm{N}^{\circ} 6$ se observa que el $64,5 \%$ de los encuestados declara haber comprado alguna vez basándose solo en la reputación de la marca. Mientras el 35,5\% declara haberse basado en otros factores.

Tabla 26. Adquisición por reputación de marcas, 2020

\section{Porcentaje}

Frecuencia Porcentaje Porcentaje válido acumulado

\begin{tabular}{llcccc}
\hline Válido & Si & 287 & 64,5 & 64,5 & 64,5 \\
& No & 158 & 35,5 & 35,5 & 100,0 \\
& Total & 445 & 100,0 & 100,0 & \\
\hline
\end{tabular}

Autor: Elaboración Propia 
Figura 6. Adquisición por reputación de marcas, 2020

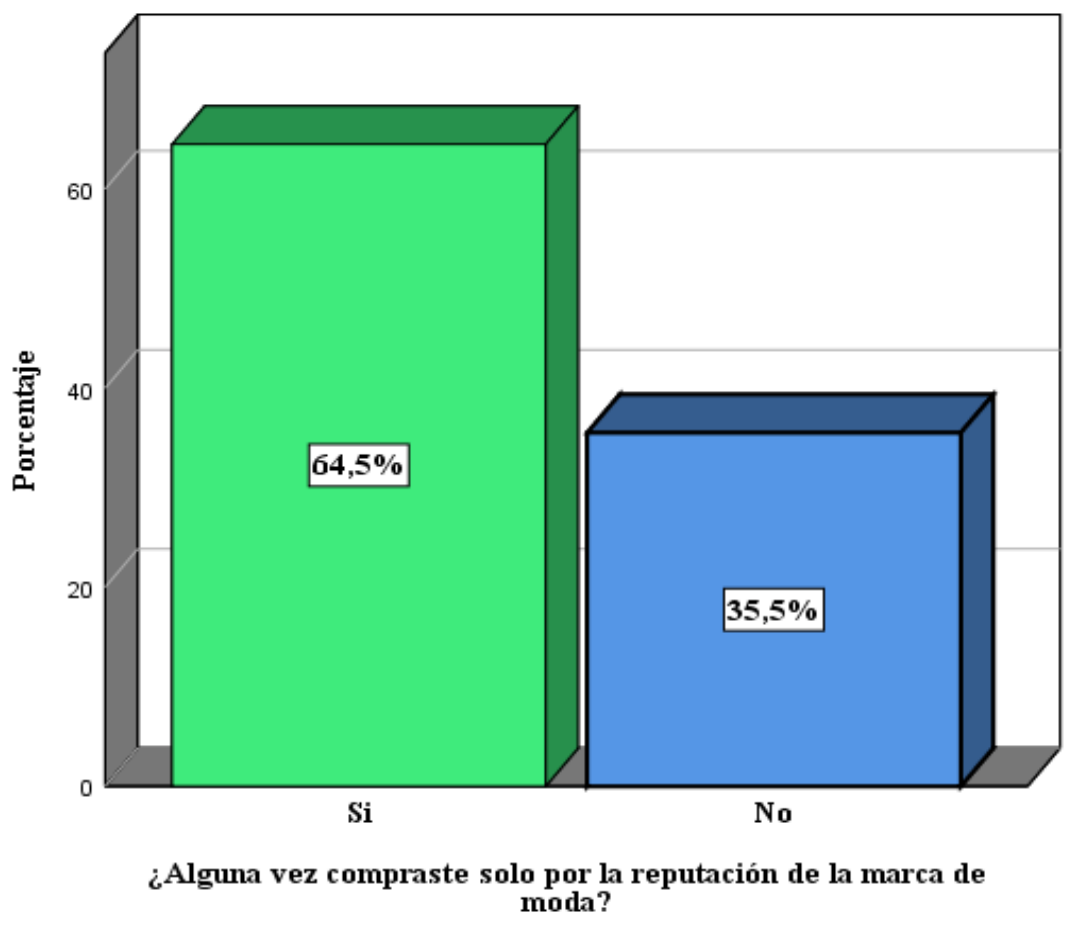

Autor: Elaboración Propia

En la siguiente tabla $\mathrm{N}^{\circ} 27$ y figura $\mathrm{N}^{\circ} 7$ se observa que el $41,1 \%$, siendo la mayoría no tuvieron ningún tipo de adquisición por recomendación de alguien más, mientras el $26.7 \%$ que sigue en mayoría tuvo la recomendación de sus amigos para la adquisición de cierto producto de moda.

Tabla 27. Adquisición de moda de los encuestados por recomendación.

\begin{tabular}{llllll}
\hline & & & & Porcentaje \\
& & Frecuencia & Porcentaje & Porcentaje válido acumulado \\
\hline Válido & Amigos & 119 & 26,7 & 26,7 & 26,7 \\
& Pareja & 26 & 5,8 & 5,8 & 32,6 \\
& Familiares & 68 & 15,3 & 15,3 & 47,9 \\
& Influencers en redes sociales & 41 & 9,2 & 9,2 & 57,1 \\
& & & 1,8 & 1,8 & 58,9 \\
& Otros & & 4 & 41,1 & 100,0 \\
& Ninguno & 183 & 41,1 & 100,0 & \\
\hline
\end{tabular}

Autor: Elaboración Propia 
Figura 7. Adquisición de moda de los encuestados por recomendación.

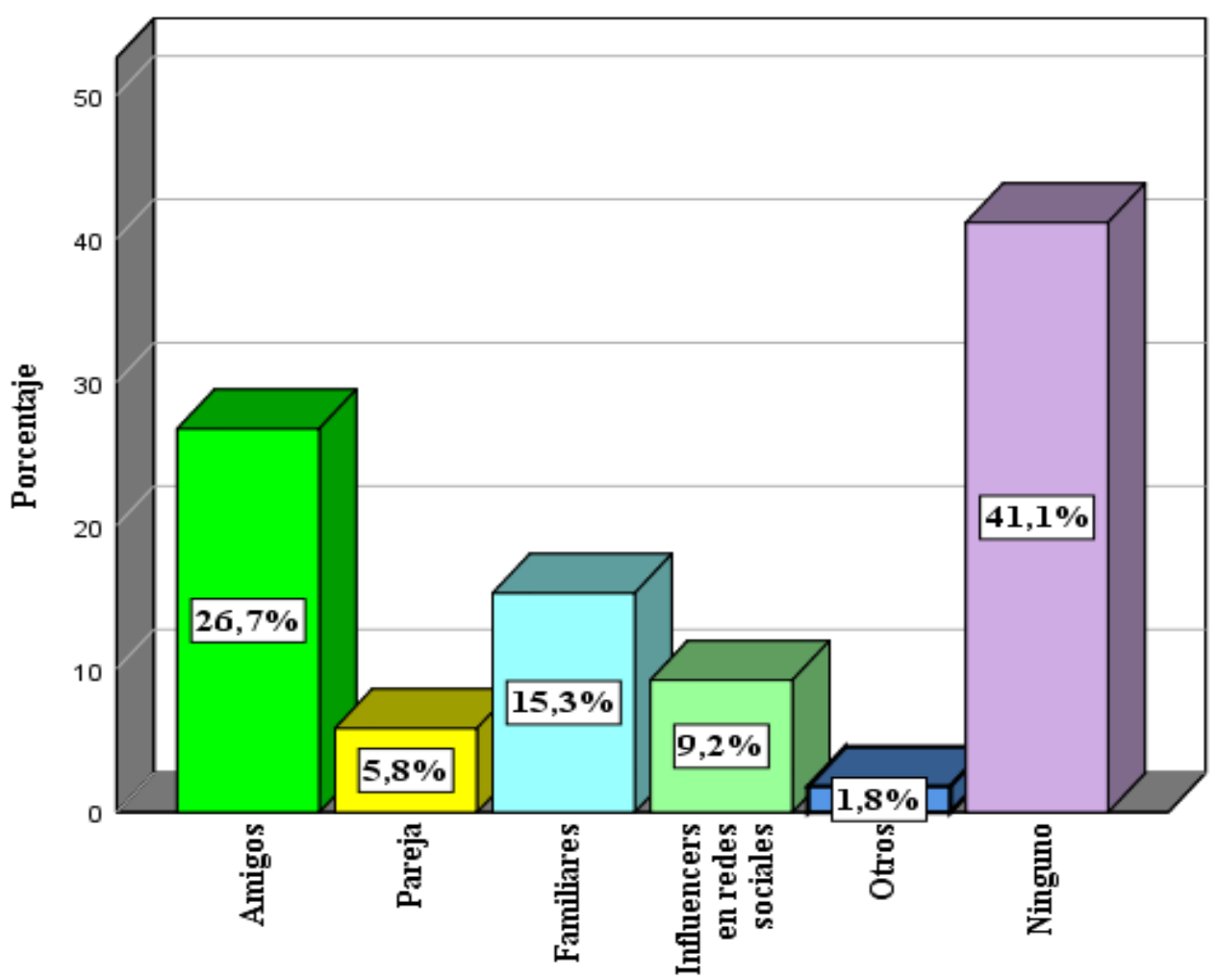

¿La ultima vez que adquiriste moda fue por recomendación de...

Autor: Elaboración Propia

En la siguiente tabla $\mathrm{N}^{\circ} 28$ y figura $\mathrm{N}^{\circ} 8$ se observa que el $51,9 \%$, suele comparar moda por internet, sin embargo, también se puede observar que el $48,1 \%$ no suele hacerlo, por lo que podemos encontrar un porcentaje relativamente equilibrado en los dos casos.

Tabla 28. ¿Sueles comprar moda por internet?

Porcentaje

Frecuencia Porcentaje Porcentaje válido acumulado

\begin{tabular}{lllccc}
\hline Válido & Si & 231 & 51,9 & 51,9 & 51,9 \\
& No & 214 & 48,1 & 48,1 & 100,0 \\
& Total & 445 & 100,0 & 100,0 & \\
\hline
\end{tabular}

Autor: Elaboración Propia 
Figura 8. Adquisición de moda por internet.

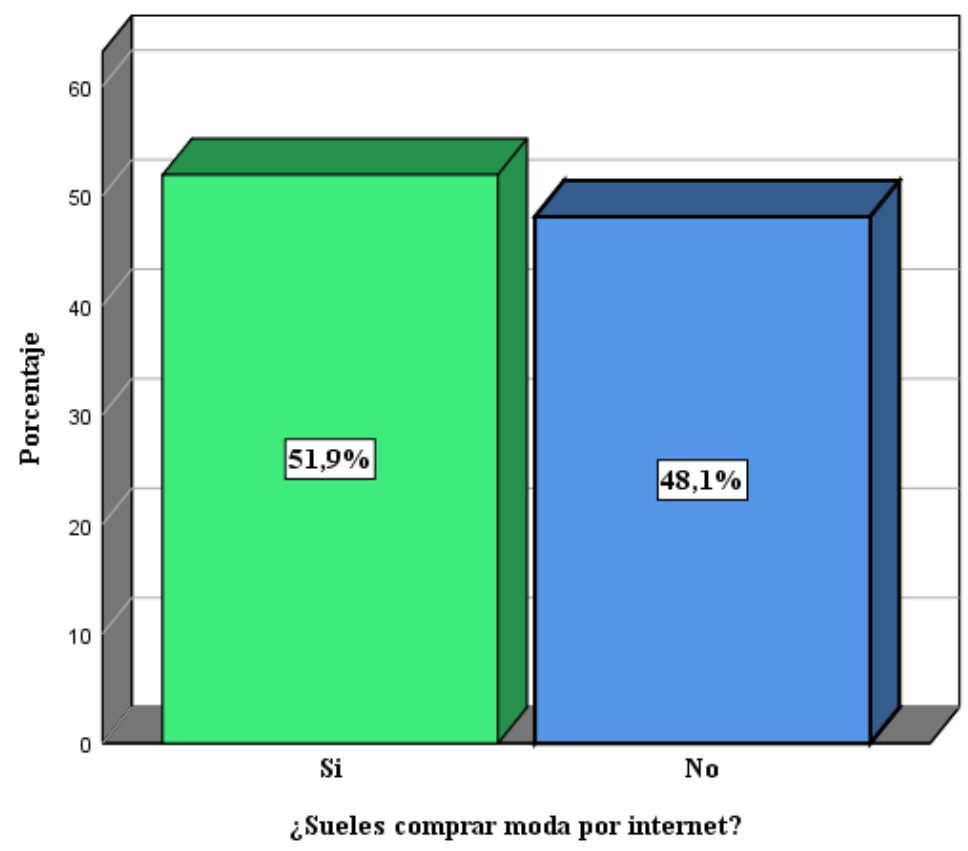

Autor: Elaboración Propia

En la siguiente tabla $\mathrm{N}^{\circ} 29$ y figura $\mathrm{N}^{\circ} 9$ se observa que el $60,2 \%$, suele visualizar publicidad sobre moda en redes sociales entre 1-5 veces al día, mientras que solo el 25,5\% asegura ver de 10 a más veces al día, y solo el 4,5\% asegura nunca ver publicidad sobre moda en redes sociales.

Tabla 29. ¿Cuántas veces promedio al día ves publicidad sobre moda en redes sociales?

Porcentaje

Frecuencia Porcentaje Porcentaje válido acumulado

\begin{tabular}{|c|c|c|c|c|c|}
\hline \multirow[t]{5}{*}{ Válido } & Ninguna & 20 & 4,5 & 4,5 & 4,5 \\
\hline & $1-5$ veces & 268 & 60,2 & 60,2 & 64,7 \\
\hline & $6-10$ veces & 88 & 19,8 & 19,8 & 84,5 \\
\hline & Más de 10 veces & 69 & 15,5 & 15,5 & 100,0 \\
\hline & Total & 445 & 100,0 & 100,0 & \\
\hline
\end{tabular}

Autor: Elaboración Propia 
Figura 9. Promedio de veces que ve publicidad de moda en redes sociales

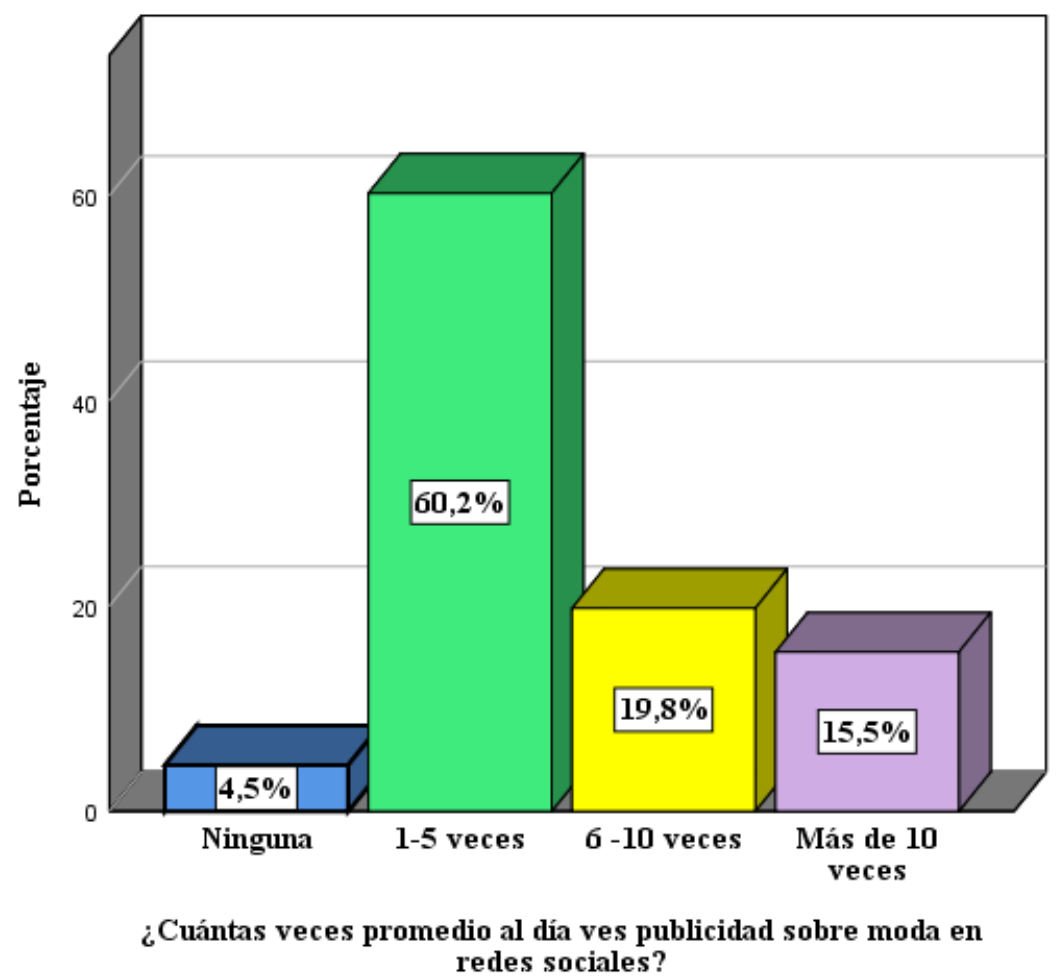

Autor: Elaboración Propia

En la siguiente tabla №30 y figura $\mathrm{N}^{\circ} 10$ se observa que el 52,1\%, siendo la mayoría "a veces" le presta atención a la publicidad sobre moda en internet, y solo el 2,9\% asegura nunca prestarle atención, al igual que solo un 5,2\% que siempre le presta atención.

Tabla 30. Según la pregunta anterior, ¿Le prestas atención a la publicidad por internet sobre moda?

\begin{tabular}{llllll}
\hline & & & & Porcentaje \\
& & Frecuencia & Porcentaje & Porcentaje válido & acumulado \\
\hline Válido & Siempre & 23 & 5,2 & 5,2 & 5,2 \\
& Casi siempre & 87 & 19,6 & 19,6 & 24,7 \\
& A veces & 232 & 52,1 & 52,1 & 76,9 \\
& Casi Nunca & 90 & 20,2 & 20,2 & 97,1 \\
& 13 & 2,9 & 2,9 & 100,0 \\
& Nunca & 100,0 & 100,0 & \\
\hline
\end{tabular}

Autor: Elaboración Propia 
Figura 10. Atención a la publicidad en internet sobre moda

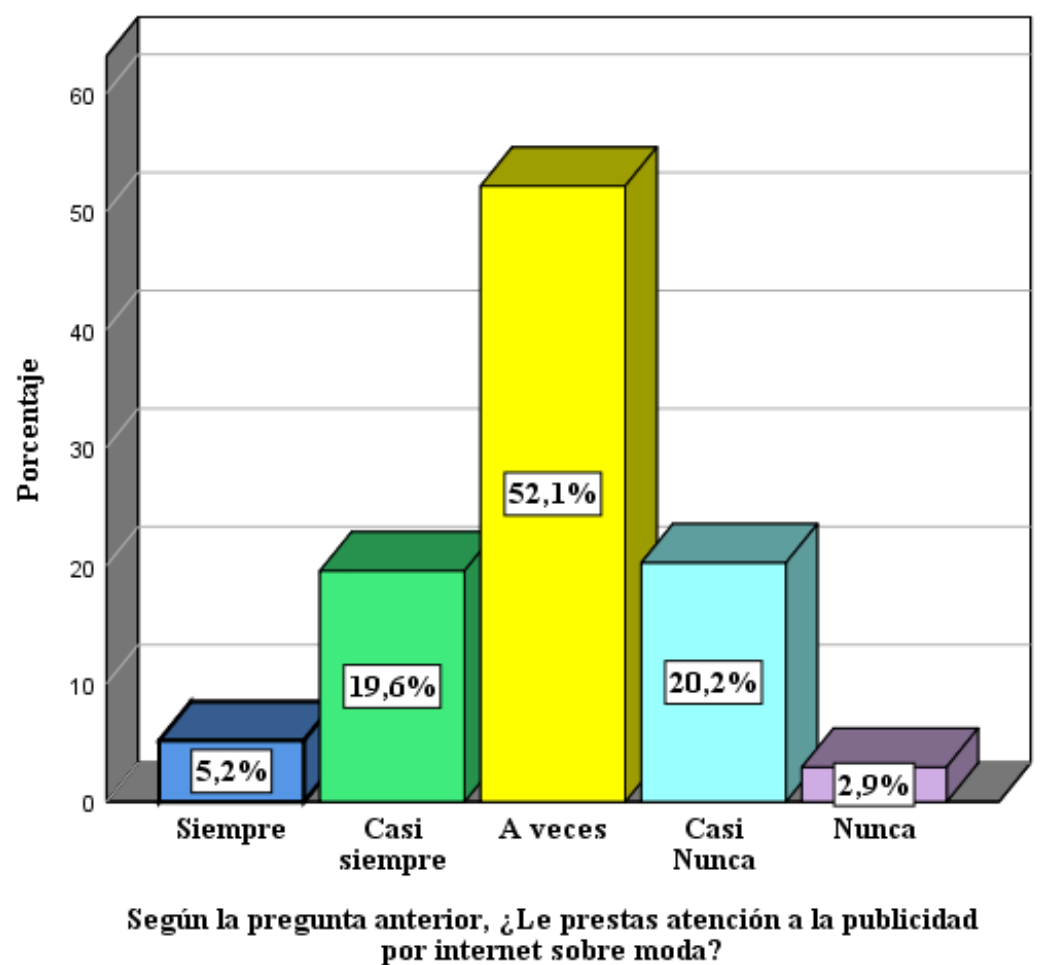

Autor: Elaboración Propia

En la siguiente tabla $\mathrm{N}^{\circ} 31$ y figura $\mathrm{N}^{\circ} 11$ se observa que el $60,4 \%$, siendo la mayoría nunca ha adquirido moda recomendada por un influencer o artista famoso, y solo el 0,9\% ha adquirido más de 10 veces.

Tabla 31. ¿Cuántas veces has adquirido moda recomendada por un influencer o artista famoso?

\begin{tabular}{llllll}
\hline & & & & & Porcentaje \\
& & Frecuencia & Porcentaje & Porcentaje válido & acumulado \\
\hline Válido & Nunca & 269 & 60,4 & 60,4 & 60,4 \\
& 152 & 34,2 & 34,2 & 94,6 \\
& $1-5$ veces & 20 & 4,5 & 4,5 & 99,1 \\
& 6-10 veces & 4 & 0,9 & 0,9 & 100,0 \\
& Más de 10 veces & 445 & 100,0 & 100,0 & \\
\hline
\end{tabular}

Autor: Elaboración Propia 
Figura 11. Adquisiciones por recomendación de un influencer o artista famoso.

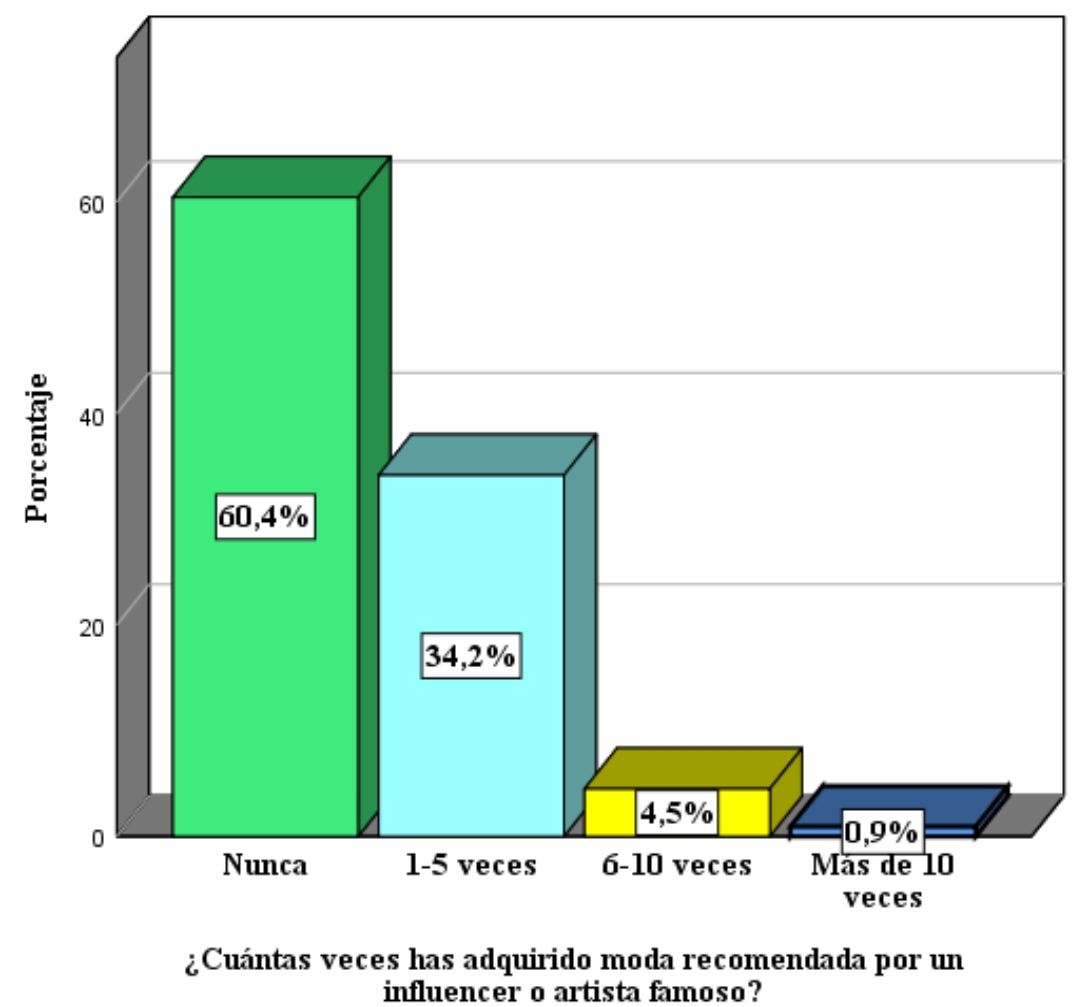

Autor: Elaboración Propia

En la siguiente tabla $\mathrm{N}^{\circ} 32$ y figura $\mathrm{N}^{\circ} 12$ se observa que, aunque el 39,6\% recuerda algún influencer/ artista famoso, solo el $29 \%$ asocia a un influencer/artista famoso a una marca de moda.

Tabla 32. ¿Qué influencers o artistas famosos te recuerdan a alguna marca de moda?

\begin{tabular}{|c|c|c|c|c|c|}
\hline & & & & Porcentaje & Porcentaje \\
\hline & & Frecuencia & Porcentaje & válido & acumulado \\
\hline \multirow[t]{5}{*}{ Válido } & Si recuerda & 176 & 39,6 & 39,6 & 39,6 \\
\hline & Recuerda y asocia a una & 129 & 29,0 & 29,0 & 68,5 \\
\hline & marca & & & & \\
\hline & No Recuerda & 140 & 31,5 & 31,5 & 100,0 \\
\hline & Total & 445 & 100,0 & 100,0 & \\
\hline
\end{tabular}

Autor: Elaboración Propia 
Figura 12. Asociación de un influencer a una marca de moda

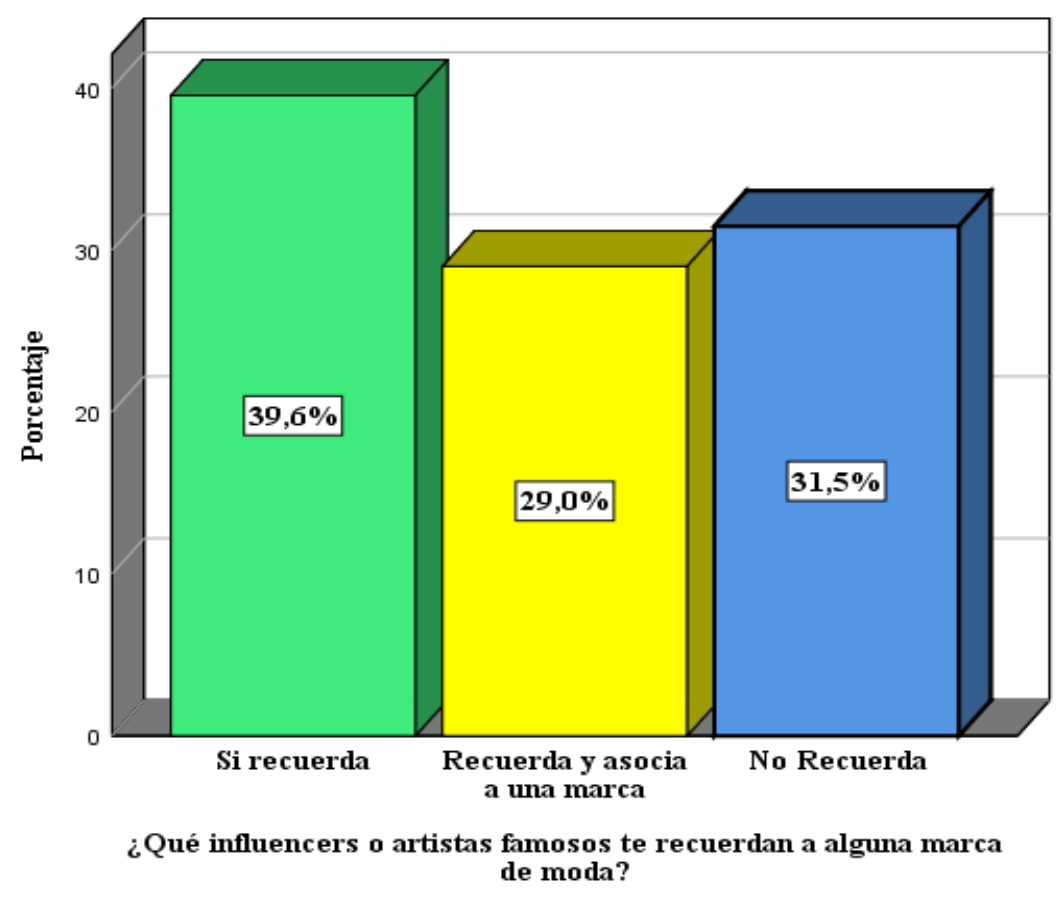

Autor: Elaboración Propia

En la siguiente tabla $\mathrm{N}^{\circ} 33$ y figura $\mathrm{N}^{\circ} 13$ se observa que el 71,9\%, siendo la mayoría si recuerda algún olor que hubiese sentido en alguna de las tiendas de marca de moda.

Tabla 33 ¿Recuerdas algún olor que hayas sentido en alguna de las tiendas de las marcas de moda a las que hayas asistido?

\begin{tabular}{llllll}
\hline & & & & Porcentaje & Porcentaje \\
& & Frecuencia & Porcentaje & válido & acumulado \\
\hline Válido & $\mathrm{Si}$ & 320 & 71,9 & 71,9 & 71,9 \\
& $\mathrm{No}$ & 125 & 28,1 & 28,1 & 100,0 \\
& Total & 445 & 100,0 & 100,0 & \\
\hline
\end{tabular}

Autor: Elaboración Propia 
Figura 13. Asociación de algún olor con una tienda de marca de moda

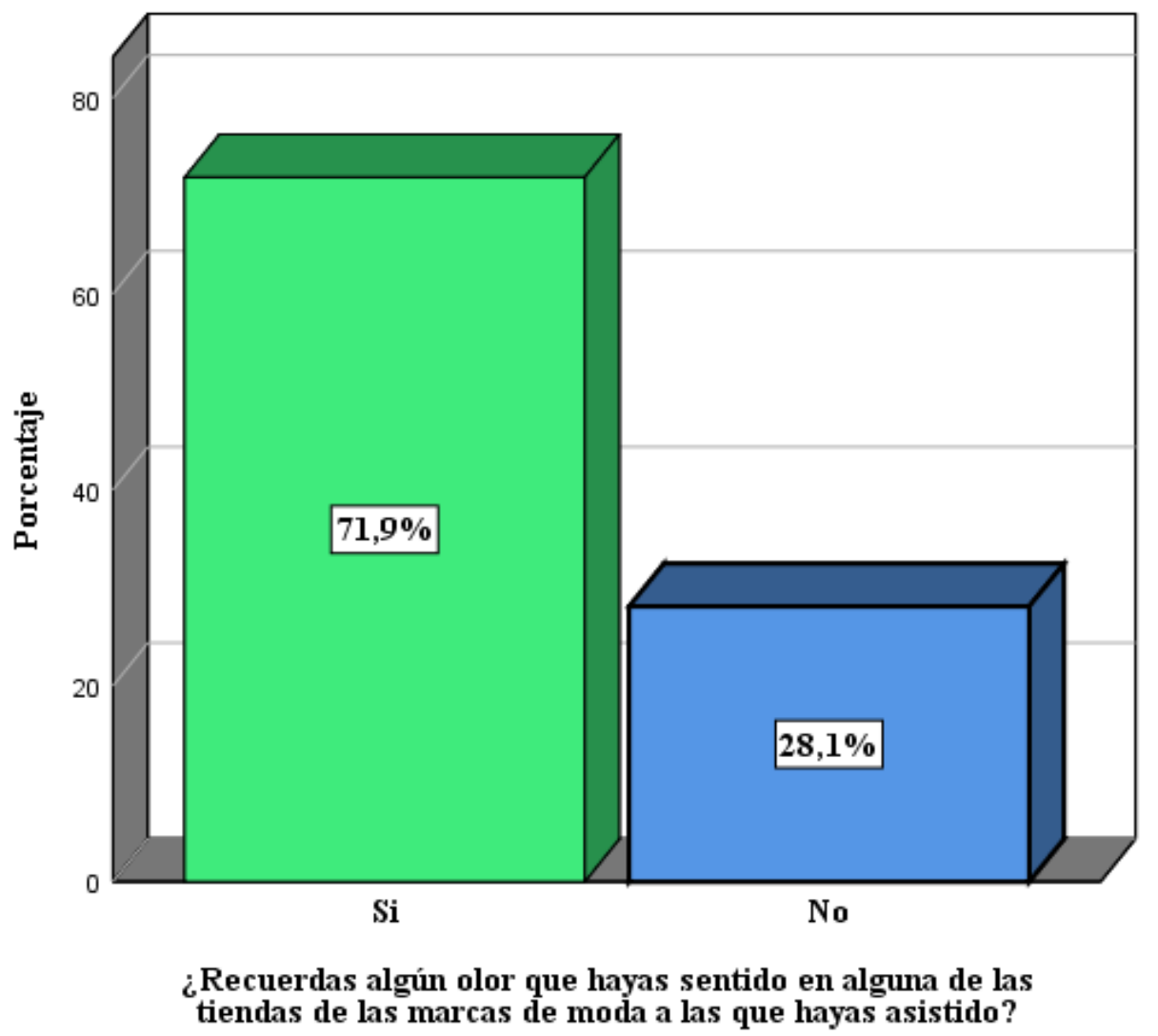

Autor: Elaboración Propia

En la siguiente tabla $\mathrm{N}^{\circ} 34$ y figura $\mathrm{N}^{\circ} 14$ se observa que el $63,8 \%$, siendo la mayoría no asocia ninguna canción a alguna marca de moda especifica.

Tabla 34. ¿Existe alguna canción que te recuerde a alguna marca de moda en específico?

\begin{tabular}{|c|c|c|c|c|c|}
\hline & & & & & Porcentaje \\
\hline & & Frecuencia & Porcentaje & Porcentaje válido & acumulado \\
\hline \multirow[t]{3}{*}{ Válido } & $\mathrm{Si}$ & 161 & 36,2 & 36,2 & 36,2 \\
\hline & No & 284 & 63,8 & 63,8 & 100,0 \\
\hline & Total & 445 & 100,0 & 100,0 & \\
\hline
\end{tabular}

Autor: Elaboración Propia 
Figura 14. Asociación de canciones con marcas de moda especificas.

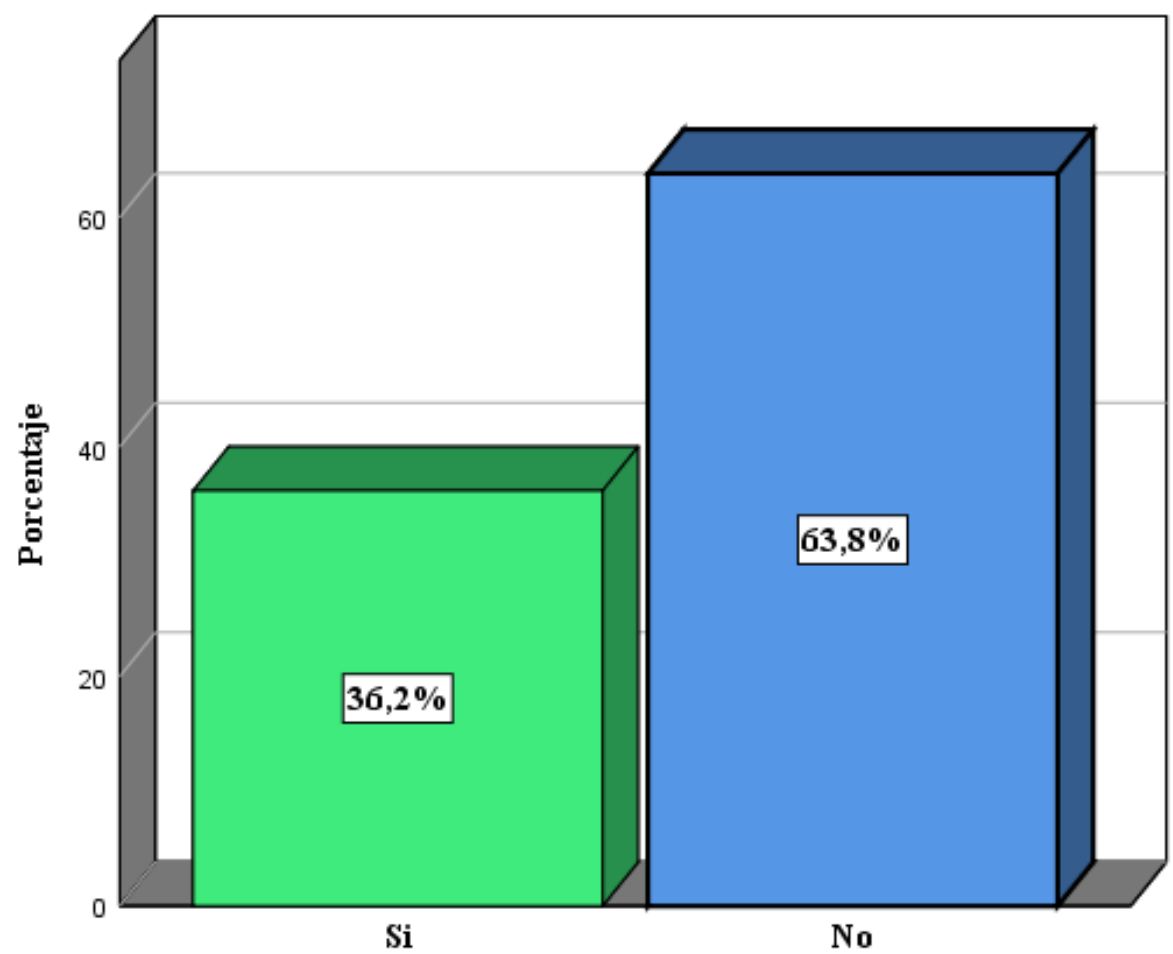

¿Existe alguna canción que te recuerde a alguna marca de moda en específico?

Autor: Elaboración Propia

En la siguiente tabla $\mathrm{N}^{\circ} 35$ y figura $\mathrm{N}^{\circ} 15$ se observa que el $60,4 \%$, siendo la mayoría declara no haber adquirido en ningún momento haber deseado adquirido una marca de moda después escuchar cierta canción o sentir cierto olor.

Tabla 35. ¿Recuerdas haber deseado adquirir cierta marca de moda luego de sentir cierto olor o escuchar cierta canción?

\begin{tabular}{|c|c|c|c|c|c|}
\hline & & Frecuencia & Porcentaje & Porcentaje válido & Porcentaje acumulado \\
\hline \multirow[t]{3}{*}{ Válido } & $\mathrm{Si}$ & 176 & 39,6 & 39,6 & 39,6 \\
\hline & No & 269 & 60,4 & 60,4 & 100,0 \\
\hline & Total & 445 & 100,0 & 100,0 & \\
\hline
\end{tabular}

Autor: Elaboración Propia 
Figura 15. Adquisición por recuerdo sensorial o auditivo.

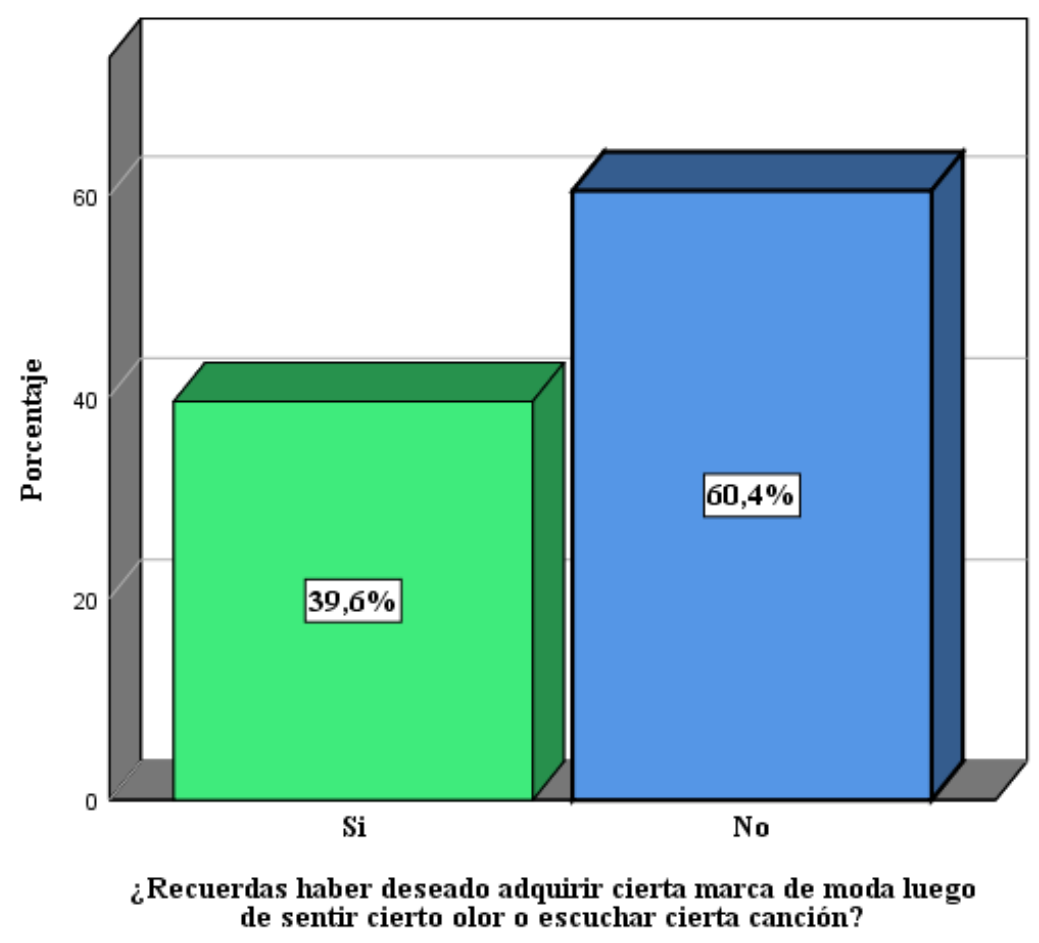

Autor: Elaboración Propia

En la siguiente tabla $\mathrm{N}^{\circ} 36$ y figura $\mathrm{N}^{\circ} 16$ se observa que el 56,9\%, siendo la mayoría declara si haber deseado adquirir una marca de moda después de visualizar algún videoclip musical.

Tabla 36. ¿Has visto marcas de moda en algún videoclip musical que te provocaran adquirir?

\begin{tabular}{llcccc}
\hline & & & & & Porcentaje \\
& & Frecuencia & Porcentaje & Porcentaje válido & acumulado \\
\hline Válido & $\mathrm{Si}$ & 253 & 56,9 & 56,9 & 56,9 \\
& $\mathrm{No}$ & 192 & 43,1 & 43,1 & 100,0 \\
& Total & 445 & 100,0 & 100,0 & \\
\hline
\end{tabular}

Autor: Elaboración Propia 
Figura 16. Visualización de marcas de moda en videoclips musicales que provocarán deseo

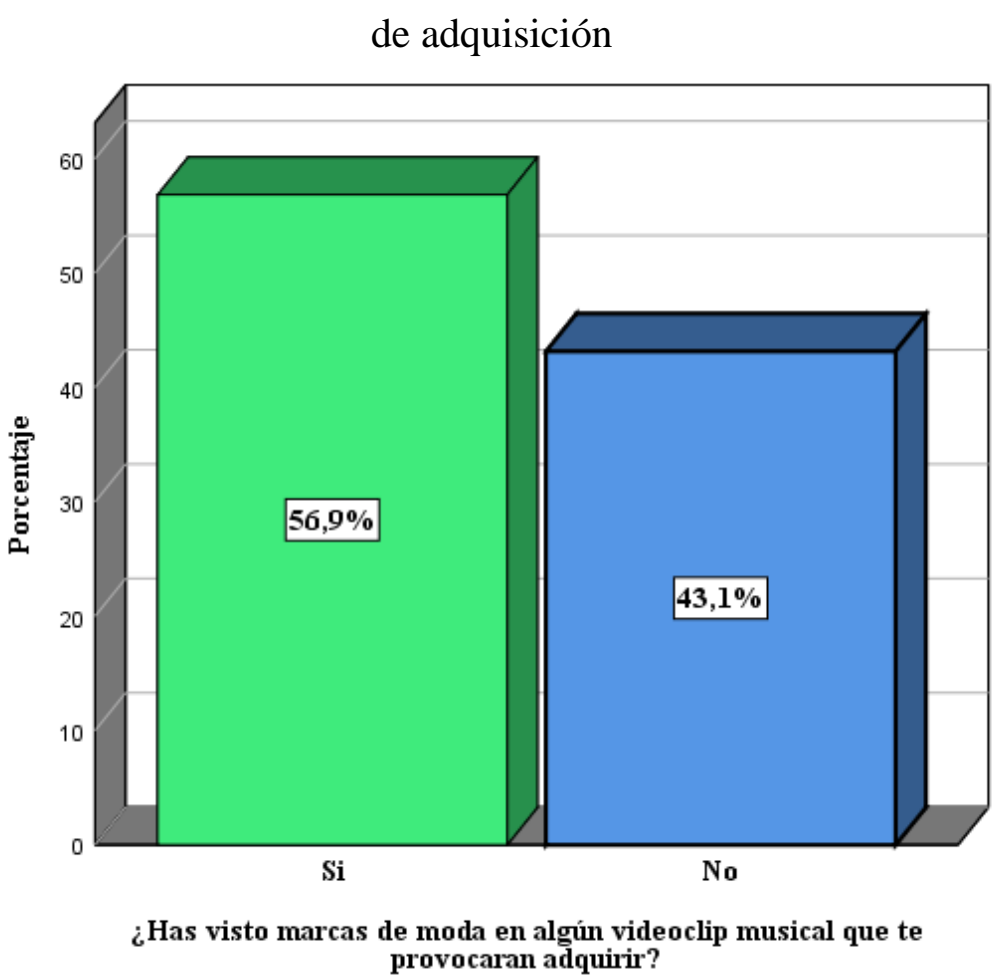

Autor: Elaboración Propia

En la siguiente tabla $\mathrm{N}^{\circ} 37$ y figura $\mathrm{N}^{\circ} 17$ se observa que el $49 \%$, siendo la mayoría declara frecuentemente realizar sus compras de moda en centros comerciales, dejando en segundo lugar con un $27.8 \%$ las compras por internet.

Tabla 37. Lugar de compras de moda frecuente

\begin{tabular}{lllll}
\hline & & \multicolumn{2}{l}{ Respuestas } & \\
\cline { 3 - 4 } & & $\mathrm{N}$ & Porcentaje & Porcentaje de casos \\
\hline ¿Dónde sueles realizar compras de Centros comerciales & 384 & $49,0 \%$ & $86,3 \%$ \\
ropa? $^{\text {B }}$ & Boutiques & 72 & $9,2 \%$ & $16,2 \%$ \\
& Showroom & 40 & $5,1 \%$ & $9,0 \%$ \\
& Internet & 218 & $27,8 \%$ & $49,0 \%$ \\
& Aplicación Móvil & 70 & $8,9 \%$ & $15,7 \%$ \\
& & 784 & $100,0 \%$ & $176,2 \%$ \\
\hline
\end{tabular}


Figura 17. Lugar de compras de moda frecuente

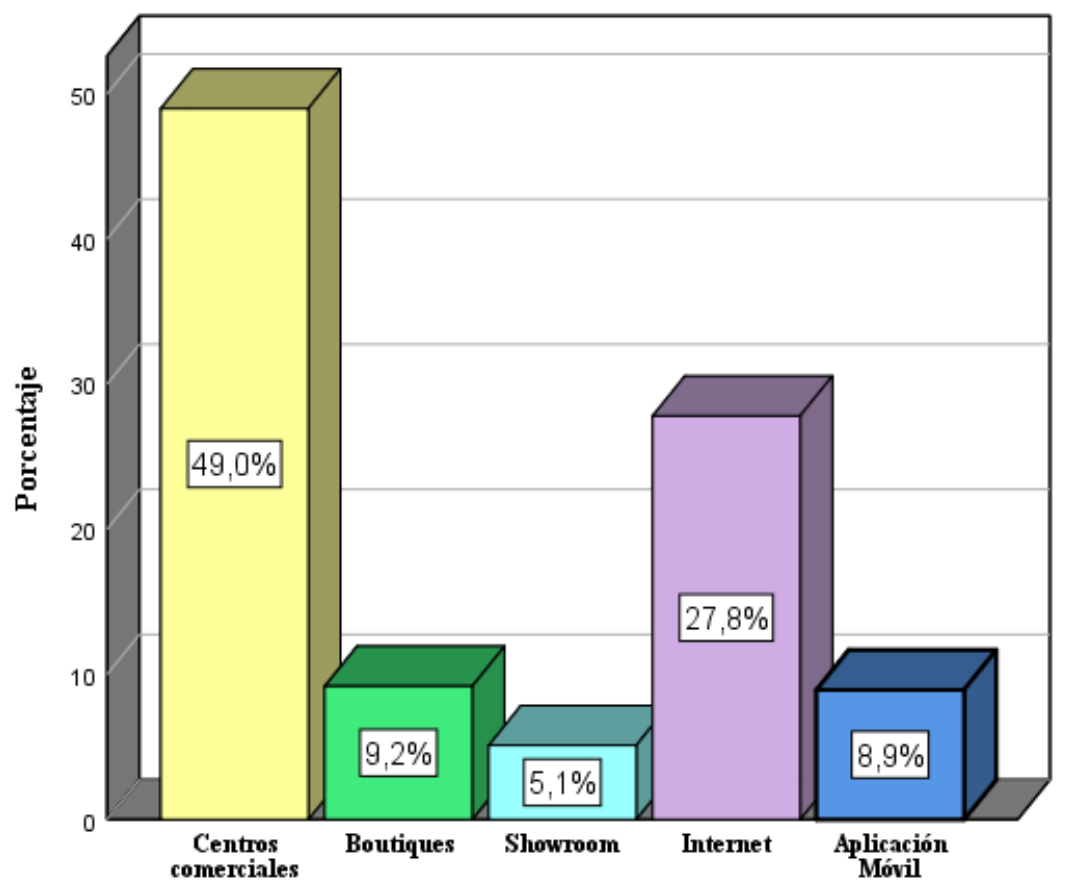

Autor: Elaboración Propia

\section{Discusión}

A partir del análisis inferencial podemos obtener que la hipótesis general se confirma, al denotarse que el branding si influye en la adquisición de productos de un retail multinacional de moda en trabajadores del distrito de Surco como se había planteado en un inicio con la limitación de la interpretación al distrito de Surco.

Así mismo en estos hallazgos pudimos obtener que el branding sensorial, si influye en la adquisición de productos de un retail multinacional de moda en trabajadores del distrito de Surco, lo que explica que los olores si son importantes para poder atraer al consumidor a adquirir los productos de moda y así mismo asociarlos en su mente a cierta marca para un posterior consumo. Es por ello por lo que muchas empresas actualmente lo aplican, empresas 
como Forever 21, H\&M, entre otros lo encuentran como un arma para ambientar a sus consumidores y poder cambiar su estado de animo al deseado para una mayor adquisición.

Por otro lado, el branding digital también se demostró influir en la adquisición de productos de un retail multinacional de moda en trabajadores del distrito de Surco tanto de forma positiva como negativa, hemos podido ver a lo largo de los últimos años como la imagen de una marca puede ser destruida en segundos a través de las redes sociales, así como la industria de la moda puede crecer desde cero solo a través del internet, empresas como gymshark y pretty little thing son perfectos ejemplos de start-ups que comenzaron en un taller en casa y que hoy en día son conocidos mundialmente gracias a la utilización de influencers y celebridades famosas a través de redes sociales, sin necesidad si quiera de tener presencia física a la fecha, apoyando los estudios de Rowley (2009) y Goswami (2015) que se señalan en los antecedentes del presente estudio que indican que la presencia web es primoridal para las marcas.

Finalmente, en cuanto a la hipótesis planteada para el Brand awareness, se demostró que, si influye en la adquisición de productos de un retail multinacional de moda en trabajadores del distrito de Surco, esto ya que muchas personas consumen solamente lo que conocen ya que lo asocian con calidad, moda y comodidad para vestir, es así como marcas como michael kors, nike o adidas han trascendido a través del tiempo.

En cuanto al análisis descriptivo, tenemos que la mayoría de los encuestados fueron mujeres con un $65 \%$ aproximadamente frente a los hombres (34\% aproximadamente), así como en su mayoría tenían entre 22 y 25 años, lo que podría hacer que este estudio este centrado mayormente en un análisis de sus respuestas. 
Así mismo tenemos que el lugar de compra preferido suele ser centros comerciales e internet, habiendo este último escalado en los últimos años, siendo una forma revolucionaria de adquisición de moda en la actualidad, especialmente entre los jóvenes debido a su alcance mundial y facilidad de consumo. En cuanto a la frecuencia de compra de los encuestados, este es en promedio de cada dos o tres meses, cada semestre o cada mes, demostrando así que el fast fashion o moda rápida, que se menciona como uno de los tipos de moda en el marco teórico, es el privilegiado entre los peruanos trabajadores del distrito de Surco. Un tipo de consumo que aunque actualmente todavía se encuentra de moda entre los peruanos, comienza a desaparecer en países más desarrollados, trayendo una tendencia de la moda lenta a países en desarrollo como el Perú.

Por otro lado, pudimos visualizar que se suele ir de compras tanto acompañado como solo, siendo preferible solo o con familia, lo que nos da a entender que los consumidores de moda del distrito de Surco consideran que la moda es un momento de adquisición muy privado, por lo que lo realizan solos o con su entorno más cercano. Asi mismo, pudimos observar que se influencian muy poco de otras personas, por lo que una vez más notamos que solo se apoyan en su familia o en ellos mismos para decidir sus adquisiciones de moda.

En cuanto a la capacidad de recordar una marca, como se pudo observar en los resultados el 94,4\% logró recordar alguna marca adquirida, lo que demuestra la hipótesis del Brand awareness y la importancia de un buen posicionamiento para que los consumidores puedan recordarlos luego de sus compras y así aumentar las posibilidades de una nueva adquisición posteriormente. Así mismo, se volvió a demostrar la hipótesis de brand awareness al poner a prueba la capacidad de recordar el logo y/o slogan de la marca adquirida con un 91,5\% de encuestados confirmando la hipótesis. Sin embargo, posteriormente encontramos que solo el 6 
$64,5 \%$ de los encuestados declara haber comprado alguna vez basándose solo en la reputación de la marca, por lo que se puede inferir que se consideran otros factores al momento de la compra y que estos factores son asociados a una marca según el rendimiento de la marca en compras anteriores, entre estos factores a considerar fueron calidad, moda, diseños, funcionalidad, comodidad, durabilidad y precio, resaltando entre ellos la comodidad y el precio principalmente, por lo que podemos denotar que el precio sigue siendo un factor muy importante en la moda entre los encuestados lo que podría explicar que la tendencia fast fashion se siga manteniendo al considerar que esta tendencia implica moda a precios bajos debido a las producciones a gran escala y bajos costos de producción lo que conlleva a bajos precios al consumidor.

Por otro lado, aunque se crea que los influencers o celebridades tienen una gran influencia al momento de compras, para la población estudiada, la influencia de otros para adquirir un producto es poca o nula, habiendo adquirido por recomendación solo de "amigos" pocas veces, continuando una vez más con la idea de que la moda es un tema muy privado y si se trata de estar al día con la última tendencia se suele no estar influenciado o en algunas ocasiones influenciado más por los amigos que por la familia, dejando de lado a los influencers con un $60,4 \%$ que nunca ha adquirido moda recomendada por un influencer o artista famoso, esto podría explicarse por el hecho de que aunque el 39,6\% recuerda algún influencer/artista famoso, solo el $29 \%$ asocia a un influencer/artista famoso a una marca de moda, lo que no permite que las adquisiciones se realicen como se esperaría, a esto se le podría sumar que un influencer suele no ser de confianza para el consumidor, ya que es una persona que esta siendo pagada para recomendar un producto sea este bueno/malo, mientras que alguien cercano y de confianza no haría ello. 
En cuanto a la adquisición de moda por internet, según se sabe el Perú poco a poco se convierte en un país cada vez más tecnológico, es así que el 51,9\% declaró comprar moda por internet usualmente, mientras que el $48,1 \%$ no suele hacerlo, encontrando que poco a poco los niveles de confianza en internet se elevan, esto podría estar motivado no solo por el desarrollo tecnológico y la influencia de redes sociales, sino también por la mayor posibilidad de adquisición a nivel mundial por este canal y las diversas facilidades de pago como contra entrega, con tarjeta y a través de plataformas desarrolladas para ello como Paypal.

Por otro lado, sobre la publicidad que se visualiza en redes sociales se pudo rescatar que las personas ven publicidad de moda entre 1-5 veces promedio al día, lo que significa al analizar los algoritmos con los que trabajan las redes sociales que estas personas en algún momento del día buscaron algo relacionado con moda o comentaron o le dieron "me gusta" a algo relacionado a ello y es por lo que posteriormente visualizarán este tipo de publicidad. Es así que, el $52,1 \%$ le presta atención de vez en cuando, lo que indica que solo "a veces" cliquean en el link o visitan la página que esta adjunta a esta publicidad para informarse sobre la marca de moda en promoción.

En cuanto al branding sensorial, se investigaron los sentidos del olfato y el oído, descubriendo que contrario a lo que creía en un inicio de la investigación la música no suele ser asociada a alguna marca, sin embargo, si suele ser un motor desencadenante de deseo de adquisición si se colocan imágenes junto a la música, lo que indica que la combinación de estos sentidos es la propicia para iniciar el deseo en la industria de la moda. Así como, el sentido del olfato es el preferido para poder estimular el recuerdo de alguna marca por largo tiempo siendo que el 71,9\% recuerda algún olor que hubiese sentido en alguna de las tiendas de marca de moda, sin embargo no es un desencadenante de adquisición por lo que podría determinarse que es 
simplemente un factor de experiencia para el consumidor, lo que aporta al momento de la compra in situ y debería ser fuertemente considerando por la industria de la moda. Esta interpretación debe considerarse siempre con la limitación al distrito de Surco. 


\section{Conclusiones}

Es así que podemos concluir que la hipotesis planteada si se cumple, al igual que cada una de las especficas mencionadas en el presente trabajo como mencionado también en las discusiones. De esta investigación se pudo conocer como el branding ha influenciado y sigue influenciando actualmente tanto a nivel nacional como internacional la adquisición de productos de la industria de la moda en retails.

Es asi que como mencionado anteriormente la hipótesis general se confirma, ya que el branding si influye en la adquisición de productos de un retail multinacional de moda en trabajadores del distrito de Surco. Sin embargo, considerando los antecedentes nacionales en nuestra investigación se confirma nuevamente las conclusiones de Kam (2017), en las que indica que aunque las marcas sean importantes, los consumidores suelen influenciarse mayormente en otros factores para su adquisición como precio y diseño, lo que tambien se ha obtenido del analisis descriptivo resultado de la presente investigación, junto a otros factores como calidad, moda y comodidad para vestirse.

Así mismo en estos hallazgos pudimos obtener que el branding sensorial, si influye significativamente en la adquisición de productos de un retail multinacional de moda en trabajadores del distrito de Surco, ya que el branding sensorial está asociado al branding awareness, aunque no en el mismo grado que el branding digital al no poder llegar a todos los sentidos que seria posible llegar si tuviese al consumidor en persona, si bien es cierto los videos musicales son desencadenantes de deseo de adquisición, este no asocia mucho a las marcas y son los olores que suelen perdurar mayormente en la mente del consumidor, algo que hoy en dia es imposible hacer si no estas fisicamente en presencia del consumidor, sin olvidar que esto 
es sobretodo un extra en la experiencia del consumidor ya que tampoco se suelen asociar a marcas especificas.

Por otro lado, el branding digital también se demostró influir en la adquisición de productos de un retail multinacional de moda en trabajadores del distrito de Surco tanto de forma positiva como negativa. Podemos ver como punto de referencia como las investigaciones presentadas en los antecedentes internacionales directos, los paises de Botswana, India y Reino Unido han utilizado el branding digital para facilitar el crecimiento de sus empresas, algo sorprendente de una u otra forma en paises en desarrollo como los dos primeros mencionados considerando su nivel tecnologico aunque haciendo hincapié en que la comunicación deberia mejorar, especialmente el dar a conocer sus valores como marca. Por otro lado, se ha podido observar que el branding digital se encuentra en gran desarrollo y tiene un gran potencial para seguir evolucionando y fidelizar cada vez más personas, estando fuertemente ligado al branding awareness al estar estos dos conectados reciprocamente, permitiendo que el trabajo de los llamados "influencers" se desarrolle facilmente gracias al boca a boca a través de las redes sociales.

Finalmente, en cuanto a la hipótesis planteada para el Brand awareness, se demostró que, si influye en la adquisición de productos de un retail multinacional de moda en trabajadores del distrito de Surco, ya que las personas del distrito mencionado suelen adquirir marcas que reconocen asociandolas a calidad, siendo asi que desconfian de nuevas marcas que puedan aparecer y no tener un conocimiento previo de estos. Cabe resaltar que este estudio es solo válido para el distrito de Surco. 


\section{Recomendaciones}

Se recomienda a los interesados en desarrollar a profundidad este tema, realizar una investigación experimental trasversal in situ para poder conocer las acciones de consumo, ya que muchas veces los estudios a través de encuestas difieren de las acciones reales de las personas, al ser estos primeros solo lo que la muestra considera mientras que en el segundo plano estan sus acciones reales, pudiendo posteriormente hacer comparaciones reales.

Otra recomendación seria enfocarse en diferentes distritos de la ciudad de Lima, ya que este podria ser un factor diferencial y comparable, al ser el distrito de Surco un distrito mayormente poblado por un nivel socioeconómico A y B, lo que podria diversificar los resultados y demostrar diferentes efectos del branding en el consumidor.

Asi mismo, es importante analizar las posibilidades de las nuevas start-ups de moda para llegar al nivel de las marcas más reconocidas y los medios a utilizarse para ello, considerando que este estudió demostró que la marca es importante sin embargo existen otros factores a considerar actualmente que podrian abrir oportunidades a los emprendedores y PYMES.

Finalmente, es importante que se considere estudiar las posibilidades de ganancia a través de los "influencers", ya que, aunque se crea es una forma de llegar al consumidor, el presente estudio coloca de cierta forma en duda este hecho, y al no existir estudios que demuestre como seleccionarlos ni como medir su efectividad, seria de gran valor para las empresas poder conocerlo como medio de desarrollo del branding en sus tres areas mencionadas: digital, sensorial y awareness. 


\section{REFERENCIAS}

Albina, A. (2017). Cultura de marca: La influencia del branding en el emprendimiento del Perú actual: bases para una plataforma de vinculación entre el diseño marcario y los emprendedores. Pontificia Universidad Católica del Perú - Facultad de Arte y Diseño. Recuperado de: http://hdl.handle.net/20.500.12404/9001

Almoguera (2016). Bienes sustitutivos y bienes complementarios. Economia Practica. Recuperado de: https://www.economiadehoy.es/noticia/9350/economiapractica/bienes-sustitutivos-y-bienes-complementarios.html

American Marketing Association (2013). Definition of Brand. USA.

Banco Santander (2019). Los elementos que componen una marca. Banco Santander. Recuperado de: https://www.bancosantander.es/es/empresas-advance/actualidad-ypymestv/itinerarios/itinerarios/marca/los-elementos-que-componen-una-marca

Cambridge University Press (2019). Meaning of product. Cambridge Dictionary. Recuperado de: https://dictionary.cambridge.org/dictionary/english/product

Cortegana, A., Gonzales, A., Gonzáles, Y. (2018). Influencers en la decisión de compra de moda deportiva: estudio del consumo de marcas Adidas, Nike y Puma de Millennials de Lima. Pontificia Universidad Católica Del Perú - Facultad De Gestión Y Alta Dirección. Recuperado de: http://tesis.pucp.edu.pe/repositorio/bitstream/handle/20.500.12404/13236/CORTEGA NA_BARRANTES_GONZALES_AYBAR_GONZ\%C3\%81LES_ROND\%C3\%93N .pdf? sequence $=1 \&$ is Allowed $=\mathrm{y}$

Dada, G. (2017). What Is Influencer Marketing and How Can Marketers Use It Effectively? Forbes. Recuperado de: https://www.forbes.com/sites/forbescommunicationscouncil/2017/11/14/what-isinfluencer-marketing-and-how-can-marketers-use-it-effectively/\#7e4513b723d1

Dimock, M. (2019). Defining generations: Where Millennials end and Generation $\mathrm{Z}$ begins. Pew Research Center. Recuperado de: https://www.pewresearch.org/facttank/2019/01/17/where-millennials-end-and-generation-z-begins/ 
Doyle, C. (2011). A Dictionary of Marketing. Estados Unidos: Oxford University Press.

Escobar, K. (2017). Branding y fidelización del cliente en el Centro Comercial Real Plaza de la provincia de Huánuco. Repositorio Universidad de Huánuco. Recuperado de: http://repositorio.udh.edu.pe/bitstream/handle/123456789/848/ESCOBAR\%20HUER TO\%2C\%20KEVIN\%20MICHAEL.pdf?sequence=1\&isAllowed=y

Goetendía, S. (2018). Influencia de la comunicación del Branding digital de los bancos en su Posicionamiento de marca en hombres y mujeres de 24 a 30 años de NSE B. Universidad Peruana de Ciencias Aplicadas (UPC). Recuperado de: https://repositorioacademico.upc.edu.pe/bitstream/handle/10757/625190/Goetendia_S L.pdf?sequence $=5 \&$ isAllowed $=\mathrm{y}$

Goswami, S. (2015). A study on the online branding strategies of indian fashion retail stores. IUP Journal of Brand Management, 12(1), 45-59. Recuperado de https://search.proquest.com/docview/1691586258?accountid=43847

Haddrick, M. (2018). The 10 Eco-Friendly Fashion Labels We Love. InStyle. Recuperado de: https://www.instylemag.com.au/eco-fashion

Ho, C. (2012). An exploratory study on relationships between factors that influence consumers' perceptions of retail branding and purchase behavior. Journal of Business \& Economics, 4(2), 143-176. Recuperado de: https://search.proquest.com/docview/1492205316? accountid=43847

IGI Global (2019). What is Fashion Retailing. IGI Global Dictionary. Recuperado de: https://www.igi-global.com/dictionary/frontline-employees-self-perception-ofageism-sexism-and-lookism/40684

Iwu, C., Jaiyeoba, O., Thamage, S., Opeda, F. (2017). Impact of retail branding on consumer buyer behaviour: A case of retail outlets in botswana. African Journal of Business and Economic Research, 12(1), 141-161. Recuperado de https://search.proquest.com/docview/1899783735?accountid=43847

Jalilvand, M., Shahin, A., Vosta, L. (2014). Examining the relationship between branding and customers' attitudes toward banking services. International Journal of Islamic and 
Middle Eastern Finance and Management, 7(2), 214-227. Recuperado de: doi:http://dx.doi.org/10.1108/IMEFM-05-2011-0018

Kam, L. (2017). La importancia de la marca en la decisión de compra del consumidor de moda: un cuasiexperimento aplicado a las jóvenes universitarias peruanas del NSE A y B (Tesis de licenciatura en Comunicación). Repositorio institucional PIRHUA. Recuperado de: https://pirhua.udep.edu.pe/bitstream/handle/11042/2880/INF_207.pdf?sequence=1

Kotler, P., Keller, K. (2015). Marketing Management. Pearson Educación, 323. Recuperado de: https://www.ebooks7-24.com:443/?il=4840

Lampert, Martijn. Global Rise in Environmental Concern. Glocalities International B.V. Recuperado de: https://glocalities.com/latest/reports/environmental-concern

Loranger, D. (2018). Redefining fashion: Retail, luxury, sales and merchandising. Fashion, Style, \& Popular Culture, 5(3), 293+. Recuperado de: http://link.galegroup.com/apps/doc/A553905395/GPS?u=usil\&sid=GPS\&xid=d0b4ef 10

Millar, C., Choi, C., Chen, S. (2005). Globalization rediscovered: The case of uniqueness and "creative industries". Management International Review, 45(1), 121-128. Recuperado de: https://search.proquest.com/docview/202720682 ?accountid=43847

Monterroso, E. (2015). Administración de las Operaciones: Tipología de Servicios. Recuperado de: http://www.unlu.edu.ar/ ope20156/pdf/servicios.pdf

Morris, C., Beresford, P., Hirst, C. (2018). Impact of food retailer branding on expectation generation and liking. Journal of Sensory Studies, 33(2), 1. Recuperado de: https://doi.org/10.1111/joss.12322

Municipalidad de Surco (2019). Plan de acción distrital de seguridad ciudadana 2019. Recuperado de: https://www.munisurco.gob.pe/wp-content/uploads/2019/05/PLANDE-ACCION-DISTRITAL-DE-SEGURIDAD-CIUDADANA-ACTUALIZADO2019.pdf

Musch, L. (2019). Slow Fashion vs Fast Fashion: A Beginners Guide. Biome. Recuperado de: https://www.biome.com.au/blog/slow-fashion-vs-fast-fashion/ 
Ochoa, Vanessa (2019). Fast fashion: ventas en Perú ya llegan a más de US\$2,000 por metro cuadrado. Gestión. Recuperado de: https://gestion.pe/economia/fast-fashion-ventasperu-llegan-us-2-000-metro-cuadrado-267418-noticia/?ref=gesr

OFX (2017). Report Strong Growth \& Expansion to New Markets, Adding Suppliers \& Hiring Skilled Talent. Marketwired. Recuperado de: https://www.ofx.com/en-us/pressroom/press-releases/2017/small-businesses-remain-confident/

PAR Marketing Services (2018). Branding. PAR Marketing Services. Recuperado de: http://parmarketingservices.com/Docs/Branding\%20White\%20Paper.pdf

Peñaranda, cesar (2019). El Perú alberga el 36\% de marcas de lujo más valiosas del mundo. Cámara de comercio de lima. Recuperado de: https://www.camaralima.org.pe/wpcontent/uploads/2020/09/190930.pdf

Real Academia Española (2018). Trabajador. Diccionario de la lengua española. Recuperado de: https://dle.rae.es/?id=aBkr9sx

Rowley, J. (2009). Online branding strategies of UK fashion retailers. Internet Research, 19(3), 348-369. Recuperado de: http://dx.doi.org/10.1108/10662240910965397

Sahay, V. (2013). Globalization, urbanization and migration: Anthropological dimensions of trends and impacts. The Oriental Anthropologist, 13(2), 305-312. Recuperado de: https://search.proquest.com/docview/1512708800?accountid=43847

Schnarch, A. (2014). Desarrollo de nuevos productos. McGraw-Hill Interamericana. Recuperado de: https://www.ebooks7-24.com:443/?il=106

Sheldrake, P. (2011). Business of Influence: Reframing Marketing and PR for the Digital Age. USA.

The World Bank (2019). GDP per capita (current US\$) - Peru. World Bank national accounts data, and OECD National Accounts data files. Recuperado de: https://data.worldbank.org/indicator/NY.GDP.PCAP.CD?end=2019\&locations=PE\&s $\operatorname{tart}=2010$

The World Bank (2019). GDP per capita (current US\$). World Bank national accounts data, and OECD National Accounts data files. Recuperado de: https://data. worldbank.org/indicator/NY.GDP.PCAP.CD?end=2019\&start=2010 
Thomas, S., Kopplen, A. (2002). Ethics and Innovation - Is an Ethical Fashion Industry an Oxymoron? RMIT University. Recuperado de: http://iffti.com.bh-in10.webhostbox.net/downloads/papers-presented/iv-HKPU,\%202002/B/386-397.pdf

TM (2019). Tipos de Branding. TM. Recuperado de: https://www.tiposdemarketing.net/2019/08/tipos-de-branding.html

UK Essays (2018). What is Fashion? UK Essays. Recuperado de: https://www.ukessays.com/essays/fashion/what-is-fashion.php?vref=1

Web Finance (2019). Goods definition. Business Dictionary. Recuperado de: http://www.businessdictionary.com/definition/goods.html

Web Finance. (2019). ¿Qué es adquisición? Definición y Significado. Business Dictionary. Recuperado de: http://www.businessdictionary.com/es/definicion/adquisicion.html

Zhang, C. (2016). Three essays on retail branding the makings of a great retail brand: Antecedents, outcomes, and retailer ad spending strategies (Order No. 10127505). Available from ProQuest Central. Recuperado de: https://search.proquest.com/docview/1809805881? accountid=43847 
ANEXOS 
Anexo 1: Matriz de Consistencia

\begin{tabular}{|c|c|c|}
\hline PROBLEMA & OBJETIVO & HIPÓTESIS \\
\hline $\begin{array}{l}\text { Problema general: } \\
\text { ¿Cuál es la influencia del branding en la adquisición de } \\
\text { productos de un retail multinacional de moda en } \\
\text { trabajadores del distrito de Surco? }\end{array}$ & $\begin{array}{l}\text { Objetivo general: } \\
\text { Identificar la influencia del branding en la adquisición } \\
\text { de productos de un retail multinacional de moda en } \\
\text { trabajadores del distrito de Surco. }\end{array}$ & $\begin{array}{l}\text { Hipótesis general: } \\
\mathrm{H}_{0} \text { : El branding influye en la adquisición de productos de un } \\
\text { retail multinacional de moda en trabajadores del distrito de } \\
\text { Surco. }\end{array}$ \\
\hline $\begin{array}{l}\text { Problemas Específicos: } \\
\text { ¿Cuál es la influencia del branding sensorial en la } \\
\text { adquisición de productos de un retail multinacional de } \\
\text { moda en trabajadores del distrito de Surco? }\end{array}$ & $\begin{array}{l}\text { Objetivos específicos: } \\
\text { Analizar la influencia del branding sensorial en la } \\
\text { adquisición de productos de un retail multinacional de } \\
\text { moda en trabajadores del distrito de Surco. }\end{array}$ & $\begin{array}{l}\text { Hipótesis específicas: } \\
\mathrm{H}_{1} \text { : El branding sensorial influye en la adquisición de productos } \\
\text { de un retail multinacional de moda en trabajadores del distrito } \\
\text { de Surco. }\end{array}$ \\
\hline $\begin{array}{l}\text { ¿Cuál es la influencia del branding digital en la } \\
\text { adquisición de productos de un retail multinacional de } \\
\text { moda en trabajadores del distrito de Surco? }\end{array}$ & $\begin{array}{l}\text { Examinar la influencia del branding digital en la } \\
\text { adquisición de productos de un retail multinacional de } \\
\text { moda en trabajadores del distrito de Surco. }\end{array}$ & $\begin{array}{l}\mathrm{H}_{2} \text { : El branding digital influye tanto positiva como } \\
\text { negativamente en la adquisición de productos de un retail } \\
\text { multinacional de moda en trabajadores del distrito de Surco. }\end{array}$ \\
\hline $\begin{array}{l}\text { ¿Cuál es la influencia del brand awareness en la } \\
\text { adquisición de productos de un retail multinacional de } \\
\text { moda en trabajadores del distrito de Surco? }\end{array}$ & $\begin{array}{l}\text { Evaluar la influencia del brand awareness en la } \\
\text { adquisición de productos de un retail multinacional de } \\
\text { moda en trabajadores del distrito de Surco. }\end{array}$ & $\begin{array}{l}\mathrm{H}_{3} \text { : El Brand awareness influye en la decisión de compra del } \\
\text { consumidor en la adquisición de productos de un retail } \\
\text { multinacional de moda en trabajadores del distrito de Surco. }\end{array}$ \\
\hline
\end{tabular}


Anexo 2. Sexo de los encuestados, 2020

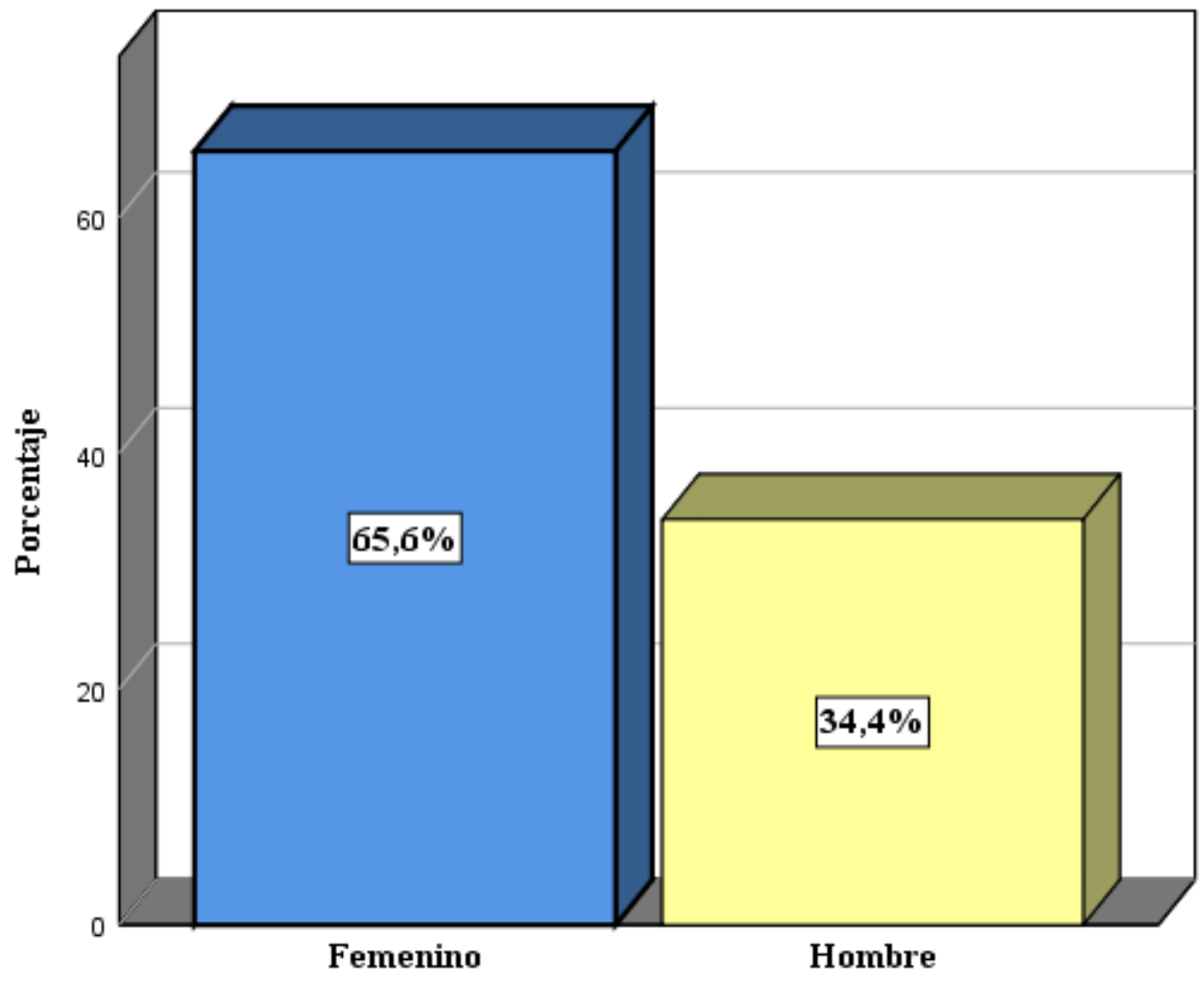

Sexo del encuestado

Autor: Elaboración Propia 
En los anexos $\mathrm{N}^{\circ} 3$ y No 4 , se observa que del $100 \%$ de los encuestados, la mayoría tienen entre 22 y 25 años. Lo cual es el 53.8\%, siendo en su mayoría de 25 años con un 16,9\%.

Anexo 3. Tabla de la edad de los encuestados, entre 20-39 años

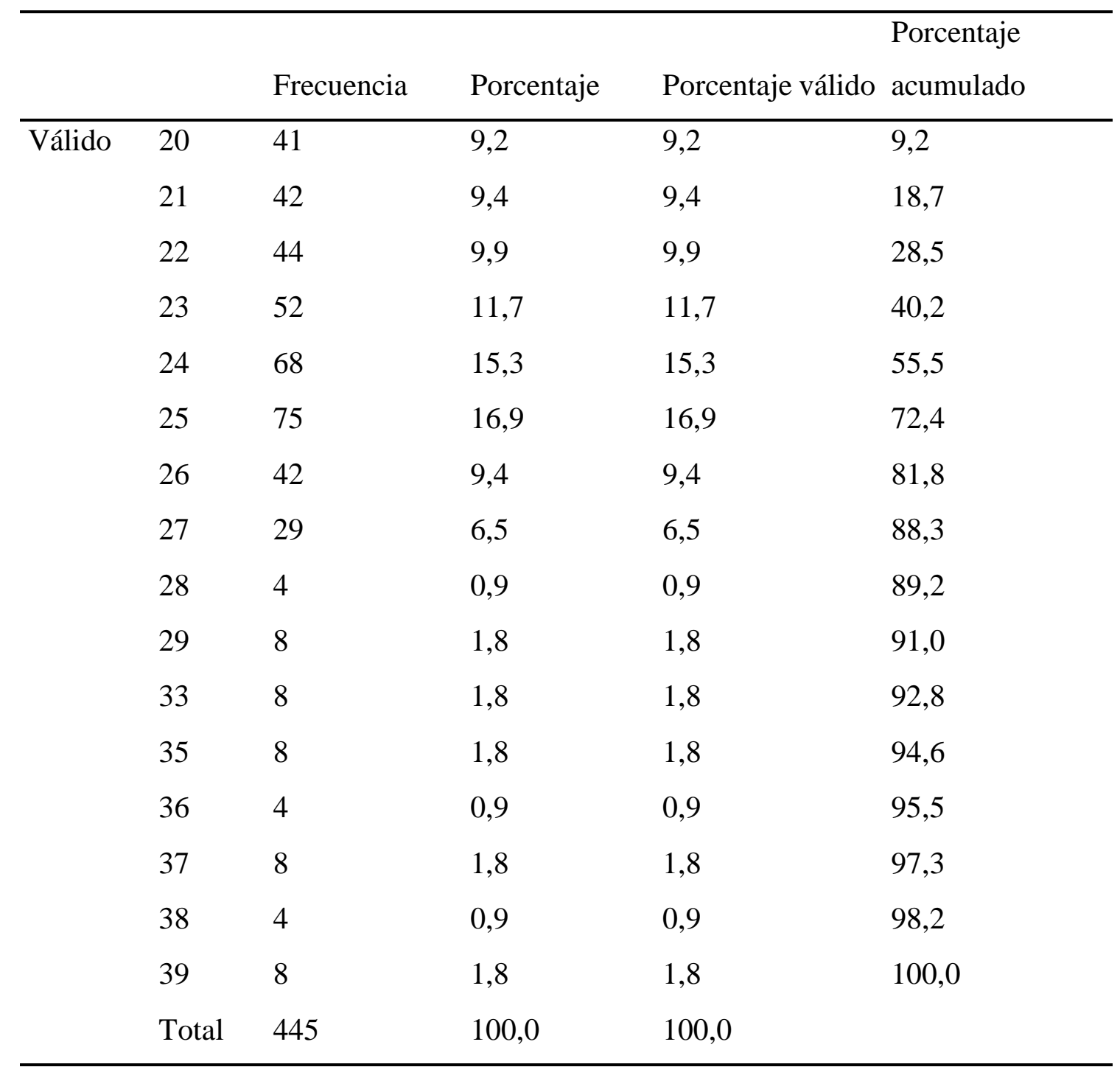

Autor: Elaboración Propia 
Anexo 4. Grafica explicativa de la edad de los encuestados, entre 20-39 años, 2020

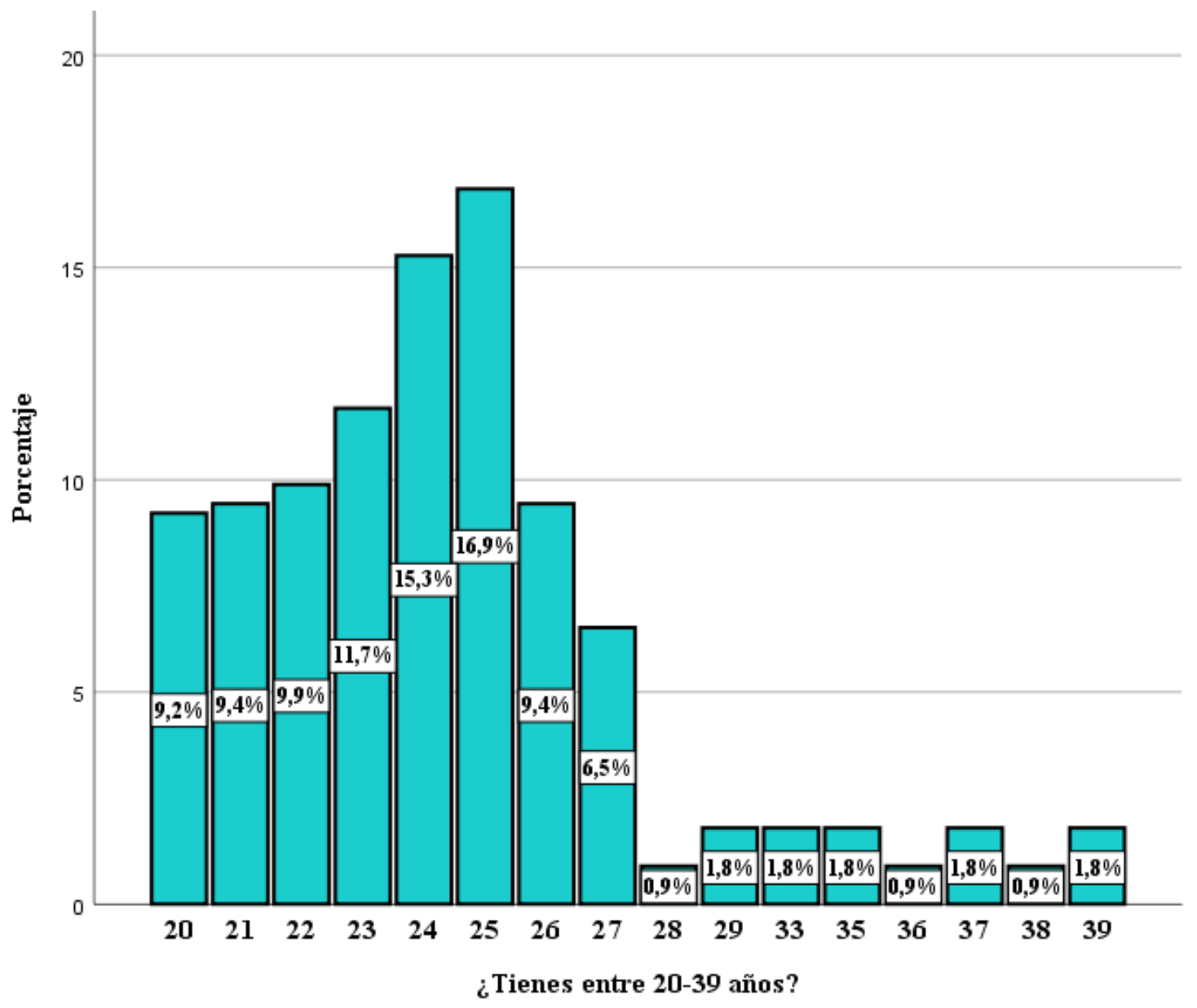

Autor: Elaboración Propia 
LXXXVIII 